\title{
LA REFORMA DE LA CONSTITUCIÓN FINANCIERA ALEMANA. EN PARTICULAR, EL NUEVO LÍMITE AL ENDEUDAMIENTO DE LA FEDERACIÓN Y LOS LÄNDER
}

\author{
EVA MARÍA CORDERO GONZÁLEZ \\ Profesora Titular de Derecho Financiero y Tributario \\ Universidad de Oviedo
}

SUMARIO

I. Introducción.

II. La Constitución financiera alemana: características generales.

III. La revisión de la Constitución Financiera en la «II Reforma del Federalismo» (2009).

IV. Consideraciones finales: perspectivas para España.

\section{INTRODUCCIÓN}

La segunda reforma llevada a cabo en la Constitución Española desde su aprobación en 1978 ha tenido por objeto, como es sabido, la modificación del artículo 135 para establecer diversos límites al endeudamiento público, cuya concreción más detallada se remite a su desarrollo a través de Ley Orgánica.

La inspiración de esta norma en los artículos 109 y 115 de la Ley Fundamental de Bonn resulta evidente tanto por su finalidad como por el proceso político que llevó a su modificación. La regulación alemana es resultado de la reforma constitucional efectuada en el año 2009 en el marco de la denominada II Reforma del Federalismo, que revisó la regulación constitucional de las relaciones financieras entre la Federación y los Länder. En el marco de dicha reforma se introdujeron también ciertas medidas tendentes a mejorar la eficiencia de la Administración tributaria a través de la coordinación de las Administraciones territoriales.

La reforma de 2009, centrada en los aspectos financieros de la Constitución, se encuadra en un proceso más amplio de revisión integral del federalismo alemán, iniciado en

1 Ya con anterioridad, en el año 2004, se produjo un intento de reforma constitucional en el mismo sentido, que no llegó a aprobarse por la falta de acuerdo sobre la distribución de las competencias en materia de educación. 
el año 2006 con la «I Reforma del Federalismo» ${ }^{1}$. Entre otros aspectos, la reforma revisó el sistema constitucional de distribución de competencias legislativas, ampliando las exclusivas de los Länder y reduciendo en cambio su participación en la aprobación de las Leyes federales a través del Bundesrat, cuya intervención había provocado en numerosas ocasiones el bloqueo del procedimiento legislativo, al tener mayoría política distinta a la del Bundestag ${ }^{2}$.

Complementariamente, la reforma de 2006 acometió también una primera y parcial revisión de las relaciones financieras federales. Así, con la finalidad de reforzar la autonomía decisoria de los Länder, y como excepción a la tendencia general de la modificación constitucional, se amplió su intervención en la aprobación de las leyes federales que implicaran obligaciones financieras para estos entes, a la vez que se suprimieron las ayudas financieras de la Federación sobre las materias de competencia legislativa exclusiva de los Estados (artículo 104b). En esta línea se amplió también, aunque muy limitadamente, la autonomía tributaria de los Länder, otorgándoles la posibilidad de determinar el tipo de gravamen de ciertos impuestos de regulación federal cuya recaudación les corresponde (artículo 105.2a). El incumplimiento de los límites comunitarios al déficit público por parte de Alemania, llevó también a introducir en la Constitución un principio de responsabilidad conjunta de la Federación y los Estados frente a las sanciones derivadas de la vulneración de obligaciones internacionales y comunitarias (artículos artículos 104a (6) y $109(5))^{3}$. La revisión más profunda de la Constitución financiera se remitió sin embargo, a la II Reforma del Federalismo, que concluyó en 2009.

$\mathrm{Al}$ análisis de esta última reforma se dedica este trabajo, prestando especial atención a la introducción de un nuevo límite al endeudamiento público para el conjunto de la Federación. Aunque los condicionantes históricos, políticos y económicos sean diversos en cada país, este estudio resulta de interés para enriquecer el debate interno en torno al artículo 135 y apuntar experiencias comparadas ante una hipotética reforma del Título VII de la Constitución española, relativo a la Economía y Hacienda. La previsible intro-

2 Hasta entonces, la Federación había adquirido un papel central en la configuración del ordenamiento jurídico, al haber hecho uso exhaustivo de las distintas posibilidades legislativas que le otorgaba el texto constitucional, aunque con la intervención de los Länder a través del Bundesrat. Las denominadas Zustimmungsgesetze, leyes que requieren el voto favorable de este órgano para su aprobación, habían pasado a ser, en contraste con la intención inicial del constituyente, la regla general, extendiéndose al setenta por ciento de las leyes federales. Cfr. S. OETER, y J. WOLFF, «La posición del Bundesrat tras la reforma del federalismo», Revista Española de Derecho Constitucional Europeo (ReDCE), núm. 6, 2006, págs. 102 y ss y M. A. MARTÍN VIDA «La reforma del Federalismo alemán. Cambios en el reparto material de competencias entre la Federación y los Länder», ReDCE, núm. 6, 2006, pág.163. Sobre este fenómeno de centralización legislativa, sus causas y consecuencias, vid. también, E. ALBERTÍ ROVIRA Federalismo y cooperación en la República Federal Alemana, Centro de Estudios Constitucionales, Madrid, 1986 y, más recientemente, A. ARROYO GIL, El federalismo alemán en la encrucijada, Centro de Estudios Políticos y Constitucionales, Madrid, 2006 y La reforma constitucional del federalismo alemán. Estudio crítico de la $52^{a}$ Ley de modificación de la Ley Fundamental de Bonn, de 28 de agosto de 2006, Institut d'Estudis Autonòmics, 2009.

3 Sobre la reforma de la Constitución financiera en el año 2006 vid. nuestro trabajo en J. M. LÓPEZ TEJERIZO (dir.) La financiación territorial en los Estados descentralizados. Un estudio comparado, IEF, 2009 y E. M. CORDERO GONZÁLEZ «La proyectada reforma de la Constitución Financiera alemana: la redistribución del poder tributario entre la Federación y los Länder», en VVAA, Estudios jurídicos en memoria de don César Albiñana García-Quintana Vol. 3, 2008, págs. 3141-3166. 
ducción en las Constituciones de otros Estados miembros de la Unión Europea de cláusulas similares restrictivas del endeudamiento público, impulsada especialmente por Alemania, acrecienta también el interés por conocer la regulación constitucional de este país.

\section{LA CONSTITUCIÓN FINANCIERA ALEMANA: CARACTERÍSTICAS GENERALES}

Para comprender el alcance y contenido de la reforma constitucional de 2009 es necesario partir de una descripción previa del origen y características generales de la ordenación de la actividad financiera en la Ley Fundamental y, en particular, de la configuración de las relaciones financieras entre la Federación y los Estados. Al hilo de esta descripción se hará referencia a algunas de las modificaciones introducidas en el año 2006, apuntando también las efectuadas en 2009, que se analizarán con más detalle en el siguiente apartado.

Bajo la denominación de «La Hacienda», el Título X de la Ley Fundamental regula, entre otros aspectos: los criterios de distribución del gasto público entre la Federación y los Estados (artículo 104); el reparto de las competencias tributarias _tanto legislativas (artículo 105) como sobre el rendimiento obtenido (artículo 106) y de aplicación de los tributos (artículo 108); el sistema de compensación financiera interterritorial (artículo 107); el presupuesto de los entes territoriales (artículos 109-113), la contabilidad y auditoria pública (artículo 114) y los límites al endeudamiento público (artículo 115).

El actual modelo de relaciones financieras federales tiene su origen en la reforma llevada a cabo en el año 1969 sobre la Ley Fundamental de Bonn del año 1949. Desde entonces, y hasta las efectuadas en 2006 y 2009, el modelo había quedado prácticamente inalterado, sobreviviendo incluso a la reunificación. La reforma vino motivada, en consecuencia, por la insuficiencia de este modelo para hacer frente a una situación económica, política y social completamente diversa a la existente en el momento de su creación ${ }^{4}$. El propio Tribunal Constitucional Federal, en su Sentencia de 19 de octubre de 2006 había manifestado la urgencia de revisar en profundidad las relaciones financieras interterritoriales, ante la insuficiencia del marco constitucional vigente para lograr la adecuada dotación financiera de estos entes 5 .

El modelo de relaciones financieras interterritoriales surgido de la reforma constitucional de 1969 presuponía, en efecto, cierta equiparación en la capacidad financiera y necesidades de gasto de los distintos Länder, realizando una distribución del poder tributario vertical _entre la Federación y los Estados_y horizontal _entre cada uno de ellos_, coherente con tal circunstancia. Tal modelo de financiación, aplicado a las nuevas condiciones socioeconómicas surgidas tras la reunificación se vio incapaz de dotar a los

4 Vid. Sobre la falta de adecuación de la Constitución financiera al vigente marco socio-económico, el informe presentado por el Prof. J. WIELAND, a la Comisión para la modernización de las relaciones financieras. Schriftliche Stellungnabme für die öffentliche Anbörung am 22. Juni 2007, págs. 1 y 2. y F. EKARDT, y D. BUSCHER, «Zur Reform der Finanzbeziehungen von Bund, Länder und Kommunen», Die Öffentliche Verwaltung (DÖV), núm. 3/2007, págs. 89-90.

5 BVerfG, 2 BvR 2023/06 vom 19.10.2006. 
Länder de recursos suficientes para el adecuado cumplimiento de sus funciones. Las diferencias económicas entre los Estados alemanes se refleja no sólo en su recaudación tributaria, que apenas pueden incrementar al carecer prácticamente de capacidad de decisión en este terreno, sino también en sus diferentes necesidades de gasto. Los Länder de menores ingresos han de hacer frente a un elevado gasto social, predeterminado en buena medida por las Leyes federales. Las transferencias de nivelación han adquirido, con ello, una importancia extraordinaria, pero se han mostrado insuficientes para el correcto funcionamiento del sistema en su conjunto.

La necesidad de reforma vino motivada también por la preocupación existente ante el elevado endeudamiento que desde hace décadas padecen tanto la Federación como los Länder y que llevó, en los años previos al debate sobre la modificación constitucional, al incumplimiento en varias ocasiones de los compromisos comunitarios en materia de estabilidad y crecimiento económico. Las causas de esta situación deficitaria son diversas y se analizarán con posterioridad, al hilo del examen del límite introducido en la reforma de 2009. Previamente nos referimos a las características generales del sistema trazado en el Título X de la Ley Fundamental.

\section{Detallada Regulación COnstitucional}

La pervivencia del modelo surgido de la reforma de 1969 resulta especialmente llamativa si se tiene en cuenta que una de las principales características de la Constitución financiera alemana es el grado de detalle de su regulación. En ella se enumeran, por ejemplo, el listado de impuestos que corresponden a cada nivel territorial, a la vez que se ordena pormenorizadamente la distribución de las competencias legislativas y de aplicación de los tributos que ostentan cada uno de ellos ${ }^{6}$.

Las reformas de 2006 y 2009 han mantenido este carácter de la Constitución. En la efectuada en el año 2006 se introdujo, por ejemplo, la responsabilidad conjunta de la Federación y los Länder en las sanciones impuestas por la Unión Europea por incumplimiento de las exigencias de disciplina presupuestaria de conformidad con el artículo 104 del Tratado de la Comunidad Europea (artículo 126 del vigente Tratado de Funcionamiento de la Unión Europea). El artículo 109.5 de la Ley Fundamental fija, en efecto, en un 65\% la parte de la sanción que soportará el Bund, imponiendo a los Länder el 35\% restante. De esta cuantía, el $35 \%$ se repartirá solidariamente entre la totalidad de los Länder, mientras que el $65 \%$ restante se exigirá a cada Estado en particular en función de su contribución a la comisión de la infracción.

El nuevo límite al endeudamiento introducido en la reforma de 2009 acentúa el tecnicismo de los preceptos constitucionales dedicados a regular la actividad financiera, pues como luego veremos, contempla márgenes estrictos al endeudamiento del conjunto del Estado, al menos en relación con el de carácter estructural.

6 Sobre el reparto territorial de las competencias financieras en Alemania, vid, entre la doctrina española J. M. TEJERIZO LÓPEZ, (dir.) La financiación territorial en los Estados descentralizados. Un estudio comparado, ob.cit, págs. 21 y ss; VVAA, El sistema de financiación territorial en los modelos de estado español y alemán, Instituto Nacional de la Administración Pública, Madrid, 2000; A. GARCÍA FRÍAS, «La financiación de los Länder», Revista Catalana de Dret Public, num. 32, 2006, págs. 233-266. 
El detalle de la regulación alemana y de la distribución de las competencias financieras entre los distintos niveles territoriales, contrasta con la existente en nuestro país, donde el desarrollo de las potestades financieras de las Comunidades Autónomas se remite a una Ley Orgánica, contemplando el texto constitucional tan sólo directrices y principios generales. El artículo 135 de la Constitución española recoge también una regulación más abierta y principialista del límite al endeudamiento público que sus equivalentes 109 y 115 de la Ley Fundamental, con remisión a la normativa comunitaria y a una Ley Orgánica para su desarrollo.

\section{Predominio de la Federación en la definición de las potestades TRIBUTARIAS DE LOS LÄNDER}

El modelo federal alemán se caracteriza asimismo por el papel predominante de la $\mathrm{Fe}$ deración en la configuración de algunas de las potestades financieras de los Länder, fundamentalmente en relación con sus ingresos tributarios. La centralización política iniciada durante la República de Weimar, unida a las exigencias financieras de la reconstrucción tras la primera guerra mundial, otorgaron a la Federación un papel preeminente en este terreno, pese a la descentralización que, promovieron los aliados tras la guerra en otros ámbitos de la estructura política federal ${ }^{7}$.

La Federación ostenta, en efecto, un papel preponderante en la configuración del sistema tributario estatal, pues le corresponde la regulación de casi todos sus impuestos, siendo no obstante en muchos casos preceptiva la intervención del Bundesrat para la aprobación de las leyes federales. La Federación tiene competencia exclusiva, aunque con extensos límites derivados de las normas comunitarias, sobre los impuestos cuyo rendimiento le corresponde también exclusivamente, en particular, los derechos aduaneros y los monopolios fiscales. Sobre las figuras impositivas más relevantes ostenta, sin embargo, competencia legislativa concurrente con los Länder, que, a pesar de su denominación, no es compartida entre ambos, pues como señala el artículo 72, la potestad de los Länder sólo existirá en tanto y en la medida en que la Federación no hubiera hecho uso de su competencia mediante Ley ${ }^{8}$. De manera que la existencia de una ley federal previa, como ocurre en la mayoría de los casos, impide el ejercicio de las facultades legislativas de los Länder. Su intervención

7 Durante el II Reich, la fortaleza de los Estados, unidos por un vínculo contractual que mantenía su poder en el seno de la Federación, tuvo también su reflejo en el campo financiero, en el que las transferencias de los Länder constituían el ingreso principal de aquella, que disponía de escasos recursos propios. La centralización de los poderes financieros en la Federación se inició con la instauración de la República de Weimar y se plasmó en la Ley Fundamental del Bonn de 1949. Para una visión más amplia de las relaciones financieras en Alemania, vid. J. J. FERREIRO LAPATZA, «El reparto de competencias financieras en la República Federal de Alemania», Documentación Administrativa, num. 181, 1979, págs. 41 y ss y E. ALBERTÍ ROVIRA, Federalismo y cooperación en la República Federal alemana, ob.cit, págs. 269 y ss.

8 Entre la doctrina alemana, H. MEYER, destaca que el uso de esta expresión para aludir a las competencia concurrente resulta «desconcertante», puesto que los Länder casi bajo ninguna circunstancia razonable pueden entrar a regularlos. Stellungnahme zum Fragenkatalog der Föderalismuskommission II (Documento núm. 11), pág. 20. 
se reduce al asentimiento que debe otorgar el Bundesrat para la aprobación de las leyes federales, según establece de forma expresa el artículo 105.3 de la Constitución.

Así concebida, son objeto de potestad legislativa concurrente, aquellos tributos en los que se dé alguna de estas dos circunstancias:

a) Que su rendimiento corresponda total o parcialmente a la Federación, según los artículos 106 y 107 de la Constitución. Dicha competencia legislativa se extiende a los impuestos sobre la renta de las personas físicas, el impuesto sobre sociedades y el impuesto sobre el valor añadido, cuya recaudación es compartida entre la Federación y los Estados y a otros tributos cuya recaudación compete sólo a la Federación, en particular: 1) Los impuestos sobre consumos específicos, con la exclusión del impuesto sobre la cerveza, cuya recaudación corresponde exclusivamente a los Länder, y los impuestos sobre el consumo local y el lujo, que corresponden a los municipios por delegación de los Länder; 2) El impuesto sobre el transporte de mercancías por carretera; 3) Los impuestos sobre las transacciones de capital (Kapitalverkehrsteuer), el impuesto sobre los seguros y sobre las letras de cambio; 4) Los tributos extraordinarios sobre el patrimonio y los tributos compensatorios para realizar la compensación financiera; 5) Los tributos complementarios de los impuestos sobre la renta de las personas físicas y las sociedades y 6) Los tributos de carácter comunitario?.

b) Aún sin tratarse de impuestos cuya recaudación corresponda total o parcialmente a la Federación, ésta podrá utilizar sus competencias normativas cuando se den las circunstancias contempladas en el artículo 72.2 de la Constitución, es decir, cuando se haga necesaria una regulación federal para «la creación de condiciones igualitarias de vida en todo el territorio federal o la garantía de la unidad jurídica o económica en interés de todo el Estado». En ella se ha amparado, en efecto, la regulación federal de otros tributos, como los impuestos sobre sucesiones y donaciones, sobre los vehículos a motor, sobre las loterías, y otros enumerados en el artículo 106.2, cuyo rendimiento corresponde íntegramente a los Länder ${ }^{10}$. La reforma llevada a cabo en 2006 modificó puntualmente estas normas para otorgar a los Länder la posibilidad de determinar el tipo de gravamen del impuesto que grava la adquisición de bienes inmuebles y la transmisión y constitución de derechos reales sobre los mismos — Grunderwerbsteuer(artículo 105.2a), cuya recaudación les corresponde.

Finalmente, los Länder ostentan competencias exclusivas sobre los impuestos locales sobre el consumo o el lujo, siempre que no resulten equivalentes a otros impuestos regulados por la Federación. Esta disposición limita sobremanera la capacidad legislativa de los Länder en materia tributaria, circunscrita a una concreta materia imponible, sometida a la prohibición de doble imposición y vinculada, además, a recursos destinados a los municipios. Los rendimientos derivados de los impuestos locales sobre el

9 Hemos adoptado la denominación de cada uno de estos tributos utilizada por GARCÍA FRÍAS, en su trabajo, «La financiación de los Länder», antes citado.

10 El ejercicio de la competencia federal sobre estos tributos se ha cuestionado por H. MEYER, por considerar discutible la concurrencia del presupuesto de hecho que justifica la intervención federal en su regulación. Para este autor no es posible considerar que la existencia de regímenes distintos en el impuesto sobre sucesiones pueden trastocar la unidad económica del país cuando en cada municipio se aplican tipos distintos en el impuesto sobre actividades económicas (Gewerbesteuer), Stellungnabme zum Fragenkatalog der Föderalismuskommission II, ob.cit., pág. 20. 
consumo y el lujo que pudieran establecerse constituyen, en efecto, ingresos de los municipios, según dispone el artículo 106.6 de la Constitución.

A la Federación y a los Estados les está vedado, por otra parte, la exigencia de impuestos distintos a los que se enumeran en la lista tasada que contempla la Constitución, aunque como ha señalado la doctrina, la flexibilidad de los términos empleados permite el encaje, en cada uno de ellos, de diversas figuras tributarias ${ }^{11}$. Al margen queda la posible obtención de otros ingresos de carácter tributario, tasas y contribuciones especiales, a las que no alude el artículo 105, referido sólo a los impuestos. La posibilidad de establecer estos tributos vendrá ligada, en consecuencia, al régimen ordinario de distribución de competencias legislativas entre la Federación y los Länder contemplado en los artículos 30 y $70 \mathrm{y} \mathrm{ss}^{12}$.

A la vista de las normas anteriores es evidente que los Länder carecen prácticamente de capacidad de decisión en la configuración de su sistema impositivo a no ser, a través de su intervención colectiva en el Bundesrat. La Constitución les asigna un listado tasado de impuestos cuya régimen jurídico se regula, en la práctica, mediante ley federal. Su capacidad de decisión en materia tributaria es, en este sentido, menor incluso que la que ostentan los municipios, que tienen la posibilidad de elevar los tipos de gravamen de algunos de los tributos cuyo rendimiento les corresponde, como el impuesto sobre bienes inmuebles (Grundsteuer) y el impuesto sobre actividades económicas (Gewerbesteuer), pudiendo exigir, además, recargos sobre su participación en los impuestos sobre la renta.

\section{TERRITORIALIZACIÓN DE LA RECAUDACIÓN DE LOS IMPUESTOS MÁS RELEVANTES}

La Constitución alemana distribuye también entre las distintas instancias territoriales los rendimientos obtenidos por cada impuesto. Los más relevantes tanto cualitativa como cuantitativamente son compartidos entre la Federación y los Estados (impuesto sobre la renta de las personas físicas, impuesto sobre sociedades e impuesto sobre el valor añadido). A los Länder les corresponde también los rendimientos de otros impuestos de menor capacidad recaudatoria, como el impuesto sobre sucesiones y donaciones o sobre las loterías. A ellos se añade, además, la posibilidad de participar ambos en un porcentaje de la recaudación del impuesto sobre actividades económicas, de carácter local (artículo 106.6).

La Constitución establece las directrices generales para el reparto de los impuestos compartidos entre la Federación y los Estados (distribución vertical-Vertikale Steuerverteilung) y entre estos últimos entre sí (distribución horizontal-Horizontale Steuerverteilung)

11 ORTIZ CALLE destaca que la limitación del «derecho a inventar impuestos» de la Federación y los Estados está vinculada con la detallada regulación que efectúa la Norma Fundamental de la compensación financiera interterritorial y el reparto de ingresos tributarios. Cfr. «Los límites de la competencia tributaria de los Länder en la República Federal de Alemania: una análisis comparado (I)», Impuestos, núm. 9/1999, pág. 106.

12 Cfr. E. ALBERTI ROVIRA, Federalismo y cooperación en la República Federal alemana, ob.cit., pág. 296. 
- Los impuestos sobre la renta de las personas físicas y las sociedades corresponden por mitad a la federación y los Länder, en función de lo recaudado en su territorio, según precisan los artículos 106 y 107 de la Constitución. Su participación en el impuesto sobre la renta se determina, no obstante, una vez descontada la correspondiente a los municipios, que los Länder en que se encuentran erradicados habrán de transferirles. Su reparto entre estos últimos se realiza, en función del rendimiento territorializado. Los puntos de conexión para proceder al reparto horizontal de la parte correspondiente del impuesto entre los distintos Länder se establecen en la Ley de Reparto (Zerlegungsgesetz), de 6 de agosto de 1998. Como regla general, se acude a los criterios de la residencia habitual en el impuesto sobre la renta de las personas físicas y a la existencia de un establecimiento permanente en el territorio del Land respectivo en el impuesto sobre sociedades. Los municipios no tienen participación, sin embargo, en el impuesto sobre sociedades, que se distribuye, en consecuencia, al $50 \%$ entre la Federación y los Länder.

- La recaudación por el impuesto sobre el valor añadido es igualmente compartida entre la Federación, los Estados y los Municipios. A diferencia de lo que ocurre con el impuesto sobre la renta, la participación de la Federación y los Länder en el IVA no se establece en la Constitución, sino que ha de fijarse por una ley federal con el asentimiento del Bundesrat, en la actualidad la Ley de Compensación Financiera antes citada, de acuerdo con dos principios contenidos en el artículo 106.3 de la Constitución. Su reparto debe tender, en primer lugar, a la armonización de las necesidades financieras de cada una de estas instancias territoriales, garantizándose, además, la igualdad de las condiciones de vida en todo el territorio federal. La federación y los Länder tienen derecho, por otra parte, a la cobertura de los «gastos necesarios» con sus «ingresos corrientes», siendo necesario realizar una previsión plurianual de ambas partidas, de modo que la «cuota de cobertura» (Deckungsquote) de los primeros sea, tras el reparto del IVA, similar para la Federación y los Estados ${ }^{13}$. El reparto horizontal del IVA entre los distintos Länder se lleva a cabo en función de su número de habitantes, con independencia de la recaudación obtenida o el consumo realizado en cada uno de ellos.

\section{NiVELACIÓN FINANCIERA INTERTERRITORIAL A CARGO DE LOS LÄNDER CON MAYOR CAPACIDAD FISCAL}

La Constitución alemana establece un sistema de nivelación financiera interterritorial que, con la finalidad de promover condiciones de vida equiparables en todo el territorio federal, pretende compensar las diferencias de capacidad fiscal existentes entre los Estados, favoreciendo a aquellos con menores ingresos por habitante. Sus características esenciales son la naturaleza incondicionada de los pagos de nivelación, cuyo destino decide el Estado receptor y el papel protagonista que adoptan los Estados en su funcionamiento. Las transferencias de nivelación no las realiza, en efecto, el Bund sino los Estados más ricos, cuyos ingresos tri-

13 La indefinición de los términos constitucionales ha causado numerosos conflictos en el reparto de estos fondos, existiendo propuestas de reforma que exigen su revisión. Vid. sobre este particular, R. WENDT, Umsatzsteuerverteilung zwischen Bund und Ländern, 2002, págs. 25 y ss y S. KORIOTH, Der Finanzausgleich zwischen Bund und Länder, 1997, pág. 481. 
butarios por habitante se encuentren por encima del promedio alemán, que transfieren parte de sus ingresos a aquellos que se encuentran por debajo de esa cifra. La Federación interviene para aprobar, con la intervención del Bundesrat y conforme a la remisión del artículo 107.2, la normativa básica que regula el proceso, la Ley de compensación financiera. La Federación podrá, no obstante, realizar asignaciones complementarias para garantizar la cobertura de las necesidades generales de los Länder de menor capacidad financiera. Como límite se establece, sin embargo, que el orden de los Länder, en cuanto a la capacidad financiera por habitante, no puede quedar alterado a resultas de la compensación ${ }^{14}$.

\section{Descentralización de la Administración tributaria}

Si las competencias legislativas en materia tributaria corresponden, en lo esencial, a la Federación, los Länder ocupan el papel predominante en la aplicación de los tributos, al tener encomendada la administración de la mayoría de los impuestos. Tal reparto es conforme con el esquema general de distribución de competencias entre el Bund y los Länder en la Ley Fundamental de Bonn, aunque no se corresponde con la tradición inmediatamente anterior de la República de Weimar, donde una Administración centralizada se encargaba de la aplicación de la mayoría de los tributos. En la actualidad, compete a la Administración federal sólo la aplicación de los tributos de carácter comunitario o aquéllos cuya recaudación le corresponde de forma íntegra. El resto de los impuestos, los de recaudación estatal —impuesto sobre sucesiones y donaciones, sobre vehículos de tracción mecánica y las loterías, entre otros - y los de recaudación compartida —impuestos sobre la renta, sociedades e IVA — se administran por los Länder, que habrán de transferir la parte correspondiente a la Federación.

Las normas procedimentales tributarias, codificadas en la Ordenanza Tributaria (Abgabenordnung), y el sistema de revisión son, no obstante, unitarios en todo el país. La administración de los impuestos de recaudación compartida se lleva a cabo, además, por delegación (Im Auftrag) de la Federación, lo que implica la asunción por dicho ente de importantes competencias de organización, dirección y control (Bundesaufsicht), jurídico y de oportunidad, sobre la actuación de $\operatorname{los} E^{2} \operatorname{sados}{ }^{15}$. El artículo 108 contempla,

14 Para medir la capacidad fiscal de cada Land y su condición, por tanto, de beneficiario o pagador de la nivelación, han de dividirse sus ingresos tributarios, incluyendo también los correspondientes a los municipios en él radicados, por su número de habitantes. Si la capacidad financiera, así calculada, se encuentra por debajo del promedio federal, el Estado correspondiente percibirá una transferencia que varía en su cuantía en función de la distancia que lo separe del citado promedio. Vid. las líneas generales de cálculo de estas transferencias en A. HERRERO ALCANDE y A. UTRILLA DE LA HOZ, «La viabilidad de los sistemas de nivelación en la financiación autonómica. Una aplicación para España de los modelos alemán y Canadiense», Documentos de trabajo de la Facultad de Ciencias Económicas y Empresariales, núm. 18, 2002, pags. 23 y 24.

15 Sobre el régimen jurídico de esta forma de actuación administrativa y la extensión de las competencias de la Federación en esta materia, vid., E. ALBERTI ROVIRA, Federalismo y cooperación en la República Federal Alemana, ob.cit., págs. 103-104 y, más específicamente sobre sus implicaciones en el terreno tributario, vid. entre la doctrina alemana, R. SEER, Bonner Kommentar zum GG, art. 108 GG, rn. 96 y ss y L. MÜLLER y F. C. ZEITLER, »Zunständigkeit bei der Verwaltung der Finanzen durch den Bund und die Länder «, Deutsche Steuerzeitung (DStZ/A), 1975. 
además, una cláusula flexible que permite establecer mecanismos de coordinación entre las distintas Administraciones e incluso alterar mediante delegación la distribución inicial de competencias si con ello se perfecciona y simplifica la aplicación de los tributos. La preocupación por mantener cierta uniformidad a pesar de la descentralización está latente en esta norma, que otorga libertad al legislador federal para, con la intervención del Bundesrat, trastocar el reparto inicial de funciones contemplado en el texto constitucional, sin necesidad de proceder a su reforma ${ }^{16}$.

Esta disposición ha servido de fundamento para la creación de una oficina federal centralizada (Bundeszentralamt für Steuern) que extiende sus competencias a algunas cuestiones relativas a los tributos compartidos, entre otras: 1) La gestión y recaudación de los impuestos con implicaciones internaciones; 2) El intercambio de información tributaria a nivel internacional; 3) La obtención y registro de información de trascendencia tributaria, en especial, la procedente de bancos e instituciones financieras; 4) La cooperación y coordinación con las autoridades estatales en los procedimientos de inspección tributaria, en particular, la que afecta a grandes empresas ${ }^{17}$.

Con la misma finalidad de garantizar cierta igualdad en la aplicación de los tributos, la Constitución se remite también a una ley federal que, de nuevo con aprobación del Bundesrat, establezca estándares mínimos en la organización de las autoridades administrativas y la formación de sus funcionarios. Dicha norma es la Ley de la Administración Financiera (Finanzverwaltungsgesetz) de 4 de abril de 2006, que establece también los principios generales que rigen su actuación.

\section{AutONOMía de lOS LÄNDER EN RELACiÓN CON EL GASTO PÚBLICO, LIMITADA AL DESARROLLO DE SUS FUNCIONES Y CONDICIONADA POR LA EJECUCIÓN DE LAS LEYES FEDERALES}

El artículo 109 de la Ley Fundamental dispone que la Federación y los Länder son autónomos e independientes en su gestión presupuestaria. Dado el carácter instrumental de la actividad financiera, la autonomía presupuestaria de los Länder se vincula, al igual que ocurre en nuestro país mediante el principio de instrumentalidad, con la ejecución de las competencias que tienen encomendadas ${ }^{18}$. La Constitución alemana contempla, en este sentido, el denominado principio de conexión (Konnexitätsprinzip) como criterio general de distribución de costes o asignación de gastos entre los distintos niveles territoriales. Según el artículo 104a, corresponde a la Federación y a los Estados, por separado, el gasto derivado del desempeño de sus funciones de acuerdo con los artículos 83 y siguientes. De ellos se desprende, sin embargo, que la financiación del gasto no compete al ente ti-

16 Cfr. V. SCHLETTE, «Art. 108«, Rn.4 en H.v.MANGOLDT, F. KLEIN y C. STARCK, Das Bonner Grundgesetz Kommentar, Bd 3, 2005 y FISCHER-MENSHAUSEN, »Art. 108 « Rn. 4, 8 en V. MÜNCH/KUNIG, Grundgesetz Kommentar, 1996.

17 Sus funciones se describen en el $\S 5$ de la Ley de la Administración financiera (Finanzverwaltungsgesetz), de 4 de abril de 2006.

18 Este principio se desprende del artículo 156 de la Constitución Española, cuando señala que las Comunidades Autónomas gozarán de autonomía financiera para el desarrollo y ejecución de sus competencias». 
tular de la competencia legislativa sino a quien tiene encomendada la ejecución de la Ley ${ }^{19}$. En el modelo federal alemán, tal función corresponde, como regla general, a los Länder no sólo respecto de sus propias leyes sino también en relación con las leyes federales. La Ley Fundamental de Bonn, recogiendo parcialmente la tradición federal alemana y la pretensión de las fuerzas aliadas de evitar la concentración de poder en manos federales, parte de la disociación de las competencias legislativas y ejecutivas entre el Bund y los Länder ${ }^{20}$. Además de la ejecución de las Leyes aprobadas por sus propios Parlamentos, la Constitución establece, de este modo, la presunción de que los Länder ejecutan como tarea propia las leyes federales (artículo 83), lo que implica, según el citado principio de conexión, la asunción de los gastos derivados de las mismas.

Partiendo de esta regla general, existen numerosas excepciones en las que la Federación ejecuta sus leyes o asume parte de su financiación, aún siendo aplicadas por los Länder ${ }^{21}$. Una de ellas son aquellas normas a las que alude el artículo $104 a$ párrafos tercero y cuarto, las que contemplan «la concesión de prestaciones dinerarias, prestaciones en especie evaluables en dinero y prestaciones comparables de servicios frente a terceros» pues, aún siendo aplicadas por los Länder, tales disposiciones pueden prever que la Federación costee parte de los gastos derivados de su ejecución.

La modificación de los párrafos tercero y cuarto del artículo 104a en la reforma federal de 2006 tuvo por finalidad ampliar la participación de los Länder, a través del Bundesrat, en la aprobación de estas leyes federales que implicaran un aumento de sus gastos, cualquiera que sea el importe que estén llamados a financiar. Con anterioridad, su participación sólo era necesaria cuando la ley federal estableciera prestaciones dinerarias frente a terceros y los Länder se vieran obligados a sufragar una cantidad igual o superior a un cuarto de los gastos generados por su ejecución ${ }^{22}$.

En el debate de la reforma llegó a plantearse la supresión de este modelo que liga la competencia en el gasto con la competencia para la ejecución de la norma, sustituyéndolo por el que vincula la carga financiera con la competencia legislativa ${ }^{23}$. La opinión mayoritaria sostuvo, sin embargo, la congruencia de tal principio con el modelo federal alemán, basado en la disociación subjetiva de las competencias legislativas y ejecutivas.

19 Sobre el significado e implicaciones de este principio vid. entre otros, T. MAUNZ «104a» Rn 9, en T. MAUNZ y G. DÜRIG, Grundgesetz, Loseblatt-Kommentar, C. H. Beck, 2007 y K. STERN, Staatsrecht, Bd. II, München, 1980, pág. 1138.

20 Vid sobre esta característica del Federalismo alemán, vid. E. ALBERTÍ ROVIRA, Federalismo y cooperación en la República Federal Alemana, ob.cit., págs.75 y ss

21 Sobre estas excepciones vid. E. ALBERTÍ ROVIRA, Federalismo y cooperación en la República Federal Alemana, ob.cit., págs. 95 y ss.

22 La intervención del Bundesrat en la aprobación de estas leyes justificaba especialmente porque como advierten EKARD y BUSCHER, las prestaciones que contemplan estas leyes admiten escaso margen de decisión a los Länder sobre las consecuencias financieras de su ejecución. Cfr. «Zur Reform der Finanzbeziehungen von Bund, Länder und Kommunen», ob.cit, pág. 91.

23 Se destacaba, en efecto, que el principio de «causalidad ejecutiva» como criterio de reparto del gasto ocasionaba la aparición de notables desigualdades entre los Länder, ya que la carga financiera a soportar varía según la repercusión de la ley federal sobre su estructura socio-económica. J. WIELAND, »Einen und Teilen - Grundsätze der Finanzverfassung des vereinten Deutschlands «, Deutsches Verwaltungsblatt, 1992, pág. 1186. Vid. También, como partidarios de la supresión de este criterio, D. HENKE y J. F. SCHUPPERT, Neuordnung der Finanzbeziehungen, 1993 pág. 61. 
El principio de causalidad legislativa se corresponde, como afirma KORIOTH, con una organización territorial en el que el reparto de competencias se realiza mediante campos materiales, siendo la misma entidad la que, como regla general, legisla y aplica la ley ${ }^{24}$. En el sistema alemán, la adopción de esta regla liberaría a los Länder de su responsabilidad sobre la ejecución de las normas, debiendo el Bund responder financieramente de su mala gestión. El criterio en vigor se consideró, en consecuencia, acertado si viene acompañado de mecanismos diversos que permitan a los Länder influir en la voluntad legislativa del Bund, asumiendo con ello la carga financiera de ella derivada ${ }^{25}$. En dicha tendencia profundizó la reforma del artículo 104a en 2006, reforzando el papel del Bundesrat en la aprobación de estas Leyes.

\section{LÍMITE CONSTITUCIONAL AL ENDEUDAMIENTO PÚBLICO}

La Constitución financiera alemana se caracterizó, desde su aprobación en el año 1949, y a diferencia de nuestro texto constitucional, por contemplar un límite máximo al endeudamiento de la Federación. Este límite se modificó en el año 1969 para referir el importe máximo del endeudamiento a la cuantía prevista en los presupuestos para los gastos por inversiones. La ineficacia de esta norma para frenar la contracción de deuda en el conjunto del Estado llevó a su revisión en la reforma efectuada en el año 2009, como veremos a continuación.

\section{LA REVISIÓN DE LA CONSTITUCIÓN FINANCIERA EN LA «II REFORMA DEL FEDERALISMO» (2009)}

\section{ORIGEN Y OBJETIVOS}

Como hemos señalado, la I Reforma del Federalismo introdujo algunas modificaciones de relieve en el Título $\mathrm{X}$ de la Constitución, pero remitió la revisión de las relaciones financieras federales a una etapa ulterior. A tal efecto, Bundestag y Bundesrat acordaron la creación, con fecha de 8 de marzo de 2007, de una Comisión conjunta para la «modernización de las relaciones financieras entre Bund y Länder» (Föderalismuskommission II), que habría de adaptar la Constitución financiera al vigente marco socio-economico ${ }^{26}$.

24 Cfr. S. KORIOTH, en su intervención en la Comisión para la modernizacion de las relaciones financieras a la que luego aludiremos, Stellungnahme zur öffentlichen Anbörung der Comisión von Bundestag und Bundesrat zur Modernisierung der Bund-Länder-Finanzbeziehungen am 22.Juni 2007, págs. 12 y 13.

$25 \mathrm{Vid}$, en este sentido A. BENZ, quien destaca que la ejecución de las leyes federales implica también una importante decisión en materia de gasto, a la vista de las distintas posibilidades organizativas y de desarrollo que ofrece la norma legal. Vid. su informe en la Comisión del Bundestag y Bundesrat para la Modernización del ordenamiento federal, de 4 de marzo de 2004.

26 Sobre esta modificación constitucional vid. A. ARROYO GIL, «La reforma constitucional de 2009 de las relaciones financieras entre la Federación y los Länder en la República Federal de Alemania», Revista de Estudios Autonómicos y Federales, núm. 10/2010, pág. 40-71. 
La Comisión no tuvo por objeto, sin embargo, la revisión integral de las relaciones financieras interterritoriales, centrándose desde el primer momento en dos temas primordiales: el establecimiento de una efectiva limitación al endeudamiento público y, en segundo plano, la mejora de la eficiencia de la Administración tributaria desde el punto de vista de su organización territorial. Como advierte KORIOTH, de las cuatro grandes cuestiones posibles a tratar en relación con el sistema financiero federal —autonomía en el gasto, autonomía tributaria, compensación financiera interterritorial y presupuesto y endeudamiento-, la discusión se centró prioritariamente sobre el endeudamiento, circunstancia que sorprende, por no tratarse de un tema «originariamente» federal. En el caso particular de Alemania, sin embargo, el problema del endeudamiento público adquiría una importante faceta «federal», al haber contribuido el reparto territorial de las competencias financieras al alto endeudamiento del conjunto del Estado, entre otras razones por tener los Länder plena autonomía para endeudarse y escasa capacidad de decisión para obtener otros ingresos. La estructura federal del Estado dificultaba también, en opinión de este autor, la reducción de la deuda ya existente ${ }^{27}$.

El incremento más acusado de la deuda se inició en Alemania a partir de mediados de los años setenta y se agudizó tras la reunificación ${ }^{28}$. La cifra de endeudamiento en porcentaje del PIB pasó del 38.5\% en 1991 al 64,3\% en 200529. En el año 2009, la deuda del conjunto de la Federación alcanzó el porcentaje 71,4\% del PIB, mientras que el déficit llegó a 3,2 \% del PIB, cantidades que superan en ambos casos los límites previstos, con carácter general por el Pacto de Estabilidad y Crecimiento ${ }^{30}$. El pago de los intereses de la deuda existente consumió en 2009 una cantidad equivalente al 20\% de los ingresos no crediticios, tratándose del segundo mayor gasto del presupuesto ${ }^{31}$. Entre los años 2002 y 2005 Alemania incumplió en diversas ocasiones los criterios de déficit establecidos por las normas comunitarias, incurriendo en déficit excesivo, lo que desencadenó la reforma del Pacto de Estabilidad y Crecimiento en el año 2005, para flexibilizar sus criterios.

La ineficacia del límite constitucional al endeudamiento público y la necesidad de reformarlo había sido señalada incluso por el Tribunal Constitucional en su sentencia de 9 de julio de $2007^{32}$. Entre la doctrina financiera se destacaban también los efectos negativos del elevado endeudamiento sobre la soberanía estatal, la justicia intergeneracio-

27 «Länderautonomie in der Verschuldungspolitik», en K. A.KONRAD y B. JOCHIMSEN (Hrsg.), Föderalismuskommission II: Neuordnung von Autonomie und Verantwortung, Peter Lang, 2008, págs. 31 y 32.

28 Para una exposición de la evolución de la deuda en Alemania, vid. C. RYCZEWSKI, Die Schuldenbremse im Grundgesetz, Duncker \& Humblot, Berlin, 2011, págs. 53 y ss.

29 Cfr. estos datos y su evolución en G. DANNEMANN, «Probleme der Föreralismusreform II «, Verwaltung und Management, 13 J.G. (2007), Heft 4, págs. 176-184 y en el Documento presentado por los miembros del Gobierno en la Comisión para la Modernización de las relaciones financieras entre el Bund y los Länder, (Documento núm. 5 - Berlin, 12 marzo 2007).

30 En el año 2010 estas cantidades se incrementaron respectivamente al 4,3\% y al 81,2\%. Vid. estas cifras en el documento del Ministerio Federal de Finanzas, Dritter Bericht zur Tragfähigkeit der öffentlichen Finanzen, 2011, pág. 11.

31 Cfr. C. RYCZEWSKI, Die Schuldenbremse im Grundgesetz, ob.cit, pág.19.

32 BVerfG, 2 BvF 1/04 vom 9.7.2007. 
nal y el principio democrático ${ }^{33}$. La aparición de la crisis financiera en 2008 afianzó la voluntad de la Comisión de modificar estas normas, que desembocó en la aprobación de un nuevo límite al endeudamiento orientado a los valores de referencia adoptados por las normas comunitarias y aplicable también a los Länder, aunque con variaciones importantes.

La organización de la Administración fue el segundo gran tema que ocupó los trabajos de la Comisión. En relación con la Administración tributaria se puso de manifiesto la necesidad de emprender reformas que tendieran a su centralización en la Federación o a mejorar la coordinación existente entre las Administraciones de los distintos Länder. En la reforma efectuada en el año 2009 se modificaron algunos preceptos constitucionales (artículo 91c) relativos a la Administración general, para la introducción, entre otras medidas, de estándares informáticos unificados en todo el territorio nacional. Los preceptos relativos a la Administración tributaria no llegaron a modificarse de forma sustancial, aprobándose en cambio, reformas puntuales en la organización administrativa o en la regulación de algunos de los procedimientos tributarios en la legislación ordinaria. Por su interés, haremos referencia, en todo caso, a las líneas de debate desarrolladas en la Comisión sobre la reorganización de la Administración tributaria, así como la posible ampliación de las competencias tributarias de los Länder, objeto también de debate en el marco de la reforma constitucional.

\section{LA INTRODUCCIÓN DE UN NUEVO LÍMITE CONSTITUCIONAL AL ENDEUDAMIENTO PÚBLICO.}

\subsection{Marco jurídico anterior}

Para entender el alcance de la reforma constitucional realizada, es necesario partir del límite al endeudamiento público vigente con anterioridad y analizar las causas de su ineficacia. El artículo 115 primer párrafo de la Ley Fundamental señalaba a este respecto que los ingresos procedentes de créditos no podrían superar los gastos previstos en cada presupuesto anual para inversiones. Este límite trataba de evitar que los recursos procedentes de la deuda se emplearan para sufragar gasto corriente, materializándose en cambio en inversiones que beneficiaran a quienes en un futuro habrán de contribuir para costear su devolución ${ }^{34}$ Esta cláusula no suponía, como es evidente, que el Estado contrajera crédito para invertir, dado que los ingresos procedentes de la deuda se afectan en general a la cobertura de los gastos en su conjunto, pero suponía referir el importe de la deuda a la magnitud de la inversión.

33 Vid., en este sentido, P.KIRCHHOF, «Die Staatsverschuldung als Ausnahmeinstrument», en K. GRUPP y U. HUFELD, (Hrsg.), Recht-Kultur-Finanzen, Festschrift für Reinhard Mussgnug zum 70. Geburtstag am 26. Oktober 2005, Heidelberg, 2005, págs. 131 y ss.

34 Este límite responde, en efecto, al idea expresada por Musgrave en el principio «Pay as you use», Cfr. R. A. MUSGRAVE, «Theorie der öffentlichen Schuld», en W. GERLOFF y F. NEUMARK, Handbuch der Finanzwissenschaft, 3. Band, Der öffentliche Kredit/Die Finanz- und Steuersysteme der wichtigsten Länder der Erde, Tübingen, 1958, págs. 72 y ss., citado por C. RYCZEWSKI, Die Schuldbremse im Grundgesetz, ob.cit, pág. 32. 
El artículo 115 excepcionaba, por otra parte, la regla anterior cuando se produjera una «distorsión del equilibrio económico general que requiriera mayor endeudamiento».

Los límites del artículo 115 de la Ley Fundamental quedaban, además, referidos exclusivamente a la Federación. El artículo 109 de la Constitución tan solo señalaba que la Federación y los Länder eran autónomos y recíprocamente independientes en su gestión presupuestaria y que esta habría de tener en cuenta el equilibrio económico general. Los Estados tenían, así pues, amplia autonomía para endeudarse, en contraste con su escasa capacidad de decisión sobre sus ingresos tributarios. Las Constituciones de los Länder recogían, sin embargo, límites semejantes al del artículo 115 de la Ley Fundamental, planteando idénticos problemas que la primera en cuanto a su interpretación y eficacia ${ }^{35}$.

Estas normas resultaban aplicables, por otra parte, de forma cumulativa a las obligaciones derivadas de las normas comunitarias, en aquel momento, el artículo 104 del Tratado de la Comunidad Europea (en la actualidad el artículo 126 del Tratado de Funcionamiento de la Unión Europea), que obliga a los Estados Miembros a evitar déficits públicos excesivos, y las normas que integran el Pacto de Estabilidad y Crecimiento. Se trata, en efecto, de la Resolución del Consejo Europeo de 17 de junio de 1997 y dos Reglamentos del Consejo de la Unión, uno relativo al reforzamiento de la supervisión de la situaciones presupuestarias y la supervisión y coordinación de las políticas económicas (R. 1466/1997) y otro relativo al procedimiento de déficit excesivo (R. 1467/1997, de 7 de julio). Estas normas establecen, como es sabido, límites al déficit público anual y a la deuda acumulada del $3 \%$ y $60 \%$ del PIB y contemplan sanciones diversas en caso de incumplimiento ${ }^{36}$.

El límite al endeudamiento contemplado en la Constitución alemana, en la medida en que sólo se refería al gasto por inversiones como límite máximo, no entraba en colisión con el Derecho comunitario, aplicándose ambas normas de forma complementaria ${ }^{37}$. La doctrina alemana había puesto de manifiesto, sin embargo, la necesidad de aproximar ambos límites, para propiciar a través de las normas internas el cumplimiento de las normas comunitarias. Como advertía HÄDE, el Derecho comunitario establece la disciplina presupuestaria como fin a cumplir por los Estados miembros, pero deja en manos de cada uno de ellos la adopción de las medidas internas necesarias para asegurar dicho cumplimiento. El límite constitucional anterior no cumplía esta función, pues más allá de su mayor o menor eficacia, se encontraba referenciado a un concepto diverso que los parámetros adoptados por las normas comunitarias, además de vincular sólo a la Federación. No existía así pues, en Alemania, hasta la reforma cons-

35 Para una exposición de las normas recogidas en las distintas Constituciones estatales, vid. C. RYCZEWSKI, Die Schuldbremse im Grundgesetz, ob.cit, pág. 77.

36 Como advierte U. HÄDE, Estos valores de referencia parten de la consideración de que un déficite del $3 \%$ estabiliza la deuda en un 60\% del PIB. Para ello es necesario que concurra un crecimiento nominal del $5 \%$. «Divergenz oder Konvergenz? Zur Vereinbarkeit von deutschen und europäischen Haushaltsrecht», en VVAA, Zur Reform der föderalen Finanzverfassung in Deutschland. Perspektiven für die Föderlismusreform II im Spiegel internationaler Erfahrungen, Nomos, 2008, pág. 67.

37 Vid. En este sentido, VVAA, «Das Schuldenregime für den Bund», en VVAA, Die neuen Schuldenregeln im Grundgesetz, Berliner Wissenschafts-Verlag, 2010, págs. 38 y ss. 
titucional de 2009, ninguna norma interna que tendiera a la transposición de las normas comunitarias relativas a la disciplina presupuestaria ${ }^{38}$.

\subsection{Las causas de la ineficacia del límite constitucional precedente}

La ineficacia de estos límites para frenar las tasas de endeudamiento público en Alemania se atribuyó fundamentalmente a su imprecisión y flexibilidad. El límite del artículo 115 se articulaba, en efecto, a partir de conceptos jurídicos indeterminados que, susceptibles de distinta interpretación, le restaron eficacia ${ }^{39}$. Desde el inicio de su aplicación, el concepto de inversiones fue interpretado extensamente por el Gobierno federal, lo que permitió que la gran mayoría del endeudamiento producido en Alemania tuviera lugar dentro de los márgenes de esta cláusula, sin necesidad de recurrir al supuesto excepcional previsto en el párrafo siguiente, para los supuestos en que se produjera una distorsión del equilibrio económico general ${ }^{40}$.

La primera interpretación gubernamental de este precepto permitió partir de un amplio concepto de inversiones, criticado por el Tribunal Constitucional en su sentencia de 18 de abril de 1989, que destacó también la necesidad de concretar legalmente su significado de acuerdo con el artículo 115 de la Constitución ${ }^{41}$. El legislador siguió la indicación del Tribunal Constitucional Federal pero sólo desde el punto de vista formal, dado que la Ordenanza Presupuestaria Federal (Bundeshaushaltordnung - BHO) recogió la práctica seguida hasta el momento por la Federación, considerando que el concepto de inversiones abarcaba los «gastos públicos por medidas que, desde una perspectiva macroeconómica, contenga, incrementen o mejoren los medios de producción de la economía política. Entre ellos se encuentran, por ejemplo, proyectos de construcción, adquisición de inmuebles o muebles de gran valor, adquisición de participaciones, préstamos y ayudas de inversión» ${ }^{42}$.

La doctrina financiera llegó a calificar la práctica estatal de inconstitucional, por vulnerar la finalidad de la norma, criticando, en particular, la adopción de un concepto de inversiones «brutas», que no tuviera en cuenta la depreciación de la inversión ni las desinversiones producidas a lo largo del ejercicio, dado que los ingresos generados podrían utilizarse para financiar gasto corriente ${ }^{43}$.

38 Cfr. U. HÄDE, «Divergenz oder Konvergenz? ...», ob.cit., págs.. 69 y ss.

39 Sobre el significado y la escasa operatividad que han demostrado estas normas para limitar el endeudamiento, vid. entre los documentos de la citada Comisión, los del Prof. H. MEYER, Stellungnahme zum Fragenkatalog der Föderalismuskommission II, Documento núm. 11, págs. 9 y ss y K. A. KONRAD. Stellungnahme zur öffentlichen Anbörung der Kommision von Bundestag und Bundesrat der Kommssion von Bundestag und Bundesrat zur Modernisierung der Bund-Länder-Finanzbeziehungen am 22. juni 2007, pág. 5.

40 Cfr. H. MEYER, «Solidarität und Verantwortung- Einige Bemerkungen zur Staatverschuldung», en K. A. KONRAD y JOCHIMSEN (Hrsg.) Förderalismusreform II...», ob.cit., pág. 103.

41 BVerfG Urt. v.18.04.1989, - 2 BvF 1/82, BVerfGE 79, 311 (337 y ss). La misma afirmación se reiteró en la Sentencia de 09.07.2007 - 2 BvF 1/04, BVerGE 119, 96 (137).

42 Cfr. el § 13.3 de esta Ley. El Tribunal Constitucional federal declaró en Sentencia de 09 de julio de 2007, que con la recepción de este concepto en la Ley, se había completado sólo formalmente su mandato anterior (Sentencia de 09.07.2007, 2 BvF 1/04, BVerfGE 119, 96 (143).

43 Calificando de inconstitucional la práctica estatal, vid., HÖFLING y RIXEN, en VVAA, Bonner Kommentar zum Grundgesetz, Art. 115, Rn. 280. Vid. también las críticas al concepto de inversiones brutas para con- 
La posibilidad de superar este límite de deuda cuando se produjera una distorsión del «equilibrio económico general» redujo también la eficacia de esta norma. En su sentencia de 18 de abril de 1989 antes citada, el Tribunal Constitucional Federal concretó el contenido de este concepto jurídico indeterminado por referencia a los fines recogidos en el $\S 1$ de la Ley para la promoción de la estabilidad y crecimiento económico (StWG) de 8 de junio de 1967, esto es, «la estabilidad de los precios, mayor ocupación, equilibrio económico exterior y adecuado crecimiento económico». En su jurisprudencia, el Tribunal Constitucional otorgó además, gran margen de apreciación al Gobierno sobre la concurrencia de las circunstancias habilitantes para la superación del límite anterior ${ }^{44}$.

El artículo 115 no fue interpretado, por otra parte, sistemáticamente con el artículo 109.2 de la misma norma, en su redacción anterior. Este precepto señalaba que en su gestión presupuestaria, tanto la Federación como los Länder, debían tener en cuenta «las exigencias del equilibrio económico general». Esta norma obligaba a desarrollar una política financiera sostenible, orientada a la estabilidad presupuestaria y de carácter anticíclico, de modo que el mayor endeudamiento en fases de depresión económica fuera compensado con medidas de ahorro y amortización de la deuda en fases de expansión ${ }^{45}$. Los gastos de inversión suponían — según esta doctrina - un límite máximo al endeudamiento y no una directriz general para contraerlo, que habría de tener en cuenta la exigencia de un presupuesto equilibrado a medio plazo, según podía desprenderse del artículo 109.2 de la Constitución. Aquí radica, en opinión de un buen número de autores la causa principal de las altas tasas de endeudamiento existentes en Alemania, dado que en épocas de bonanza económica se recurrió igualmente al endeudamiento para financiar inversiones, sin adoptar medidas de ahorro que permitieran amortizar la deuda anterior. Como señaló el Ministro Federal de Finanzas Steinbrück en el proceso de reforma constitucional, la política económica alemana siguió sólo parcialmente el modelo keynesiano, endeudándose en las épocas de difícil coyuntura, pero sin amortizar las deudas en las fases de expansión ${ }^{46}$.

También el Tribunal Constitucional alemán refrendó esta interpretación del artículo 109.2 en su Sentencia de 9 de julio de 2007, señalando que la finalidad del artículo 115 no era autorizar al legislador presupuestario a contraer crédito en fases de equilibrio o expansión hasta el importe de las inversiones. Este límite habría de utilizarse, en cambio, de acuerdo con las exigencias del equilibrio económico. Ya con anterioridad, en su Sentencia de 18 de abril de 1989, había destacado que el artículo 109.2 debería evitar que, incluso por debajo del límite máximo relativo a las inversiones se fuera creando una base de deuda que pusiera en cuestión la capacidad de reacción del presupuesto «ante los problemas actuales y futuros».

cretar el límite al endeudamiento, L.P. FELD, «Für eine wirksame Beschränkung der Verschuldung von Bund und Länder in Deutschland», en K. A. KONRAD y B. JOCHIMSEN (Hrsg.) Förderalismusreform II..., ob.cit., págs.. 64 y ss.

44 Vid., entre otras, las Sentencias de 18 de abril de 1989 y 9 de julio de 2007, citadas con anterioridad.

45 Cfr. K. A. KONRAD, «Für eine wirksame Beschränkung der Verschuldung von Bund und Ländern in Deutschland», en K. A. KONRAD, B. JOCHIMSEN (Hrsg.) Förderlismuskommission II..., ob.cit., pág. 77. Vid. También, en el mismo sentido, C.RYCZEWSKI, Die Schuldbremse im Grundgesetz, ob.cit, págs. 58-59.

46 Citdo por C. RYCZEWSKI, Die Schuldbremse im Grundgesetz, ob.cit, pág.58. 
El 115 GG contemplaba, además, en su segundo apartado otra excepción al límite de los gastos por inversiones. Este límite general podría excepcionarse mediante Ley federal para los denominados «patrimonios especiales» (Sondervermögen) del Bund, patrimonios creados para el cumplimiento de finalidades específicas y administrados directamente por la Federación o por terceros por delegación. Estas masas patrimoniales se desenvolvían fuera del presupuesto federal, del que recibían sin embargo transferencias, pudiendo contraer deudas cuando estuvieran autorizados a ello por la ley que los creara. Como ejemplos pueden citarse el European Recovery Program, destinado a la reconstrucción de Alemania tras la guerra o el Deustche Bundespost, patrimonio gestionado a través de empresas públicas diversas dedicadas a los servicios postales, bancarios y de telecomunicaciones. Este tipo de fondos pasaron a ser utilizados, especialmente tras la reunificación, para ampliar los límites constitucionales al endeudamiento hasta el punto de convertirse en «masas de deudas» más que de patrimonio ${ }^{47}$. La doctrina ha sido unánime en la crítica al uso de este medio para eludir el límite constitucional, falseando a la vez las estadísticas existentes sobre la deuda pública. Como luego veremos, la excepción relativa a los patrimonios especiales desaparece en la reforma efectuada en el año 2009, quedando, no obstante, vigentes las autorizaciones existentes a fecha de 31 de diciembre de 2009.

En relación con el límite del antiguo artículo 115 de la Constitución, se había destacado, así mismo, que el control de constitucionalidad que pudiera ejercerse sobre las leyes de presupuestos carecía de un adecuado efecto sancionador, dado que, además del retraso con que pudiera declarase la inconstitucionalidad, difícilmente iba a tener efectos sobre la deuda pública ya emitida ${ }^{48}$. Esta norma no estaba provista, además, de la adecuada tutela de la jurisdicción constitucional, debido a lo restringido de los sujetos legitimados para plantear el recurso de inconstitucionalidad. Sólo podían plantearlo, en efecto, el Gobierno federal, los Gobiernos de los Länder o un tercio - ahora un cuartode los miembros del Bundestag, sujetos que, o bien no estaban interesados en su impugnación, o bien difícilmente podían alcanzar el número mínimo para poder hacerlo, a la vista de las grandes coaliciones que han gobernado Alemania en los últimos años ${ }^{49}$.

\subsection{Incentivos al endeudamiento en las relaciones financieras federales}

Más allá de las causas socio-políticas que, con carácter general, explican el recurso al endeudamiento y de la ineficacia del anterior límite constitucional, existen ciertas ca-

47 Como ejemplo de «patrimonio especial», C. RYCZEWSKI cita el fondo denominado «Unidad alemana», cuya finalidad era la equiparación de las condiciones de vida en todo el territorio nacional, o los «fondos de créditos para el desarrollo». Con ellos no se trató de administrar masas patrimoniales, sino de abrir una vía adicional de endeudamiento, dado que de su dotación, más de dos tercios habría de cubrirse a través de créditos, mientras el resto procedía de transferencias del presupuesto federal. Die Schuldbremse im Grundgesetz, ob.cit, págs 60 y ss. Vid. También sobre la desaparición de la deuda de los presupuestos a través de su desplazamiento a patrimonios especiales, como causa de la ineficacia límite constitucional, L.P. FELD, «Für eine wirksame Beschränkung der Verschuldung von Bund und Länder in Deutschland», ob.cit, págs. 64 y ss.

48 Cfr. H. TAPPE, «Die neue «Schuldenbremse im Grundgesetz_Defizite (in) in der Föderalismusreform II, en Die öffentliche Verwaltung (DÖV), 2009, pág. 890. 
racterísticas específicas del modelo de reparto de competencias financieras en la República Federal Alemana, que han contribuido a engrosar su endeudamiento.

La primera de ellas ha sido el papel garante que se atribuye a la Federación ante las crisis financieras de los Länder. El denominado "Einstandspflicht», deriva del principio federal recogido en el artículo 10.1. de la Constitución y obliga tanto a la Federación como a los Länder a prestar ayuda a la corporación territorial que atraviese una «situación presupuestaria excepcional», que no pueda superar por sí misma. La mera existencia de este deber, además de estimular el endeudamiento de los Länder, ha facilitado su acceso al crédito al contar los acreedores con la garantía adicional de la Federación ${ }^{50}$.

Al regular el sistema de compensación financiera, la Constitución recoge, en efecto, junto con las transferencias ordinarias de Estado a Estado previstas en el artículo 107 II 1, 2, la concesión de ayudas federales de carácter complementario a los Länder más débiles, de acuerdo con el artículo 107 II 3. Esta norma, cuya interpretación ha dado lugar a numerosos conflictos ante el Tribunal Constitucional Federal, ha legitimado en las décadas pasadas la concesión de las denominadas «ayudas de saneamiento» («Sanierungsbilfen») a los Länder en situaciones de déficit presupuestario más grave («Haushaltnotlage»). El Tribunal Constitucional Federal destacó en su Sentencia de 24 de junio de 1986 que estas transferencias complementarias no tenían por finalidad hacer frente a las debilidades presupuestarias «consecuencia inmediata y previsible de las decisiones políticas de los Länder en el cumplimiento de sus funciones», constituyendo más bien un complemento a la nivelación financiera interestatal para aquellos con mayor desequilibrio entre sus ingresos $\mathrm{y}$ necesidades financieras ${ }^{51}$.

En Sentencias posteriores, sin embargo, el Tribunal Constitucional reconoció la exigibilidad de tales ayudas cuando el Estado atravesara por dificultades financieras graves. Así, en su Sentencia de 27 de mayo de 1992 el Tribunal estimó la existencia de esta situación en los Estados de Saarland y Bremen atendiendo, entre otros factores, a la proporción de ingresos que habían de destinar al pago de intereses, por encima del promedio de la Federación ${ }^{52}$.

La jurisprudencia posterior del Tribunal limitó de nuevo su eficacia, concibiéndolas como medidas excepcionales a aplicar cuando la crisis financiera amenazare la existencia del Land como «sujeto constitucional» y «el desempeño de sus funciones». El Land habría de haber agotado todos los medios a su alcance para resolver la crisis presupuestaria, siendo la ayuda federal la única salida posible a la misma ${ }^{53}$.

La escasa capacidad de decisión de los Länder en el terreno tributario también se ha visto como una circunstancia que ha agravado su recurso al crédito ${ }^{54}$. Como destaca KO-

49 Así lo advierte C. RYCZEWSKI, Die Schuldbremse im Grundgesetz, ob.cit, pág. 70.

50 Sobre los efectos incentivadores del endeudamiento que supone el respaldo financiero federal vid. S. KORIOTH, Stellungnabme zur öffentlichen Anbörung der Kommsion ..., ob.cit., págs. 3 y 4. Y K. A. KONRAD, Stellungnabme zur öffentlichen Anbörung der Kommision ..., ob.cit, pág 6.

$51 B \operatorname{VerfGE} 72,330$ s. 405

52 BVerfG, Urt de 27.05.1992_2BvF 1, 2/88,1/89 y 1/90, BVerfGE86, 148 (258 y ss).

53 Vid. la Sentencia del Tribunal Constitucional de 19 de octubre de 2006 en el denominado caso Berlin, ya citada.

54 Muchos autores han destacado el contraste existente entre la reducida capacidad de decisión de los Länder en ámbito tributario y su autonomía para el endeudamiento como causante de su grave incremento en las 
RIOTH, el papel de los ingresos por operaciones de crédito no es el mismo para la Federación que para los Estados, a la vista de su limitada capacidad para obtener ingresos adicionales a través de los tributos ${ }^{55}$. En ocasiones el endeudamiento ha sido también para el Bund la salida más rápida para adaptar sus ingresos a sus necesidades de gasto, dada su dificultad para alterar los impuestos compartidos, sobre los que necesita la conformidad de los Länder para poder decidir.

\subsection{El nuevo límite al endeudamiento para el Bund y los Länder: los artículos 109 y 115 de la Ley Fundamental}

Los trabajos de la Comisión para la reforma del Federalismo barajaron diversas opciones para modificar el límite al endeudamiento previsto en el texto constitucional. Entre las más relevantes, se planteó la posibilidad de mantener el límite existente, introduciendo modificaciones diversas que perfeccionaran su eficacia, o alterar por completo esta norma, formulando una nueva regla orientada a los criterios comunitarios limitativos del déficit de los Estados miembros, tesis que acabó prosperando ${ }^{56}$.

El nuevo límite al endeudamiento se recoge en los artículos 109 y 115 de la Constitución, cuyo contenido puede sintetizarse en las siguientes reglas:

1. Se establece, en primer lugar, que tanto los presupuestos de la Federación como de los Länder «deben ser equilibrados, en principio, sin ingresos provenientes de créditos», mandato que se establece, en general, en el artículo 109.3 para el Bund y los Länder y se reitera para este último en el artículo 115.3. Esta regla supone el establecimiento de un equilibrio presupuestario completo, con nulo endeudamiento, que no existía con anterioridad en la Constitución ${ }^{57}$. Se trata, sin embargo, de un punto de partida que se va flexibilizando a través de numerosas excepciones, en función del tipo de déficit a contraer, como veremos a continuación ${ }^{58}$.

2. La Constitución admite, en efecto, un componente de endeudamiento coyuntural para ambos niveles territoriales. Como es sabido, este tipo de endeudamiento trata de compensar el incremento de los gastos y la minoración de los ingresos derivados de una oscilación coyuntural de la economía ${ }^{59}$. Dentro de este concepto se distingue entre el en-

últimas décadas. Vid., entre otros, K. A. KONRAD, Stellungnabme zur öffentlichen Anhörung der Kommisión... , ob.cit., pág.5 y L. P. FELD, Schriftliche Stellungnahme für die Anbörung der Föderalismuskommission II zu den Finanzthemen am 22. juni 2007, págs. 6 y 11.

55 Para este autor, cualquier reforma constitucional que se emprendiera debería tener en cuenta estas circunstancias. Cfr. S. KORIOTH, «Länderautonomie in der Verschuldungspolitik», en K. A. KONRAD y B. JOCHIMSEN (Hrsg.) Förderalismusreform II..., ob.cit., pág. 36.

56 Sobre la existencia de estos dos posibles modelos en los trabajos previos a la reforma, vid. VVAA, «Das Schuldenregime für den Bund», en VVAA, Die neuen Schuldenregeln im Grundgesetz, Berliner Wissenschafts-Verlag, 2010, pág. 49.

57 Cfr. C. SEILER, »Konsolidierung der Staatsfinanzen mithilfe der neuen Schuldenregel «, Juristen Zeitung (JZ), 2009 pág. 723.

58 Cfr. E. REIMER en V. EPPING y C. HILLGRUBER, Grundgesetz Kommentar, München, 2009. Art. 109, Rn. 54.

59 Vid. Este concepto en SACHVERSTÄNDIGENRAT ZUR BEGUTACHTUNG DER GESAMTWIRTSCHAFTLICHEN ENTWICKLUNG (Hrsg.), Staatverschuldung wirksam begrenzen, Expertise im Auftrag des Bundesministers für Wirtschaft und Technologie, Wiesbaden, 2007, pág. 31. 
deudamiento coyuntural pasivo, producido automáticamente al percibir el Estado menos ingresos en fases de menor crecimiento económico, manteniendo el nivel de gasto público e incluso aumentándolo en algunas partidas, y el endeudamiento coyuntural activo, motivado por la realización de gastos complementarios para la estimulación de la economía, mediante la promoción de la demanda interna o la adopción de medidas para promover la ocupación ${ }^{60}$.

La Constitución prevé en este sentido que tanto el Bund como los Länder podrán aprobar normas para «la toma en consideración, de forma simétrica en expansión y recesión, de los efectos de un desarrollo coyuntural divergente de la situación normal» (art 109.Abs. 3 segunda frase). Con ello se posibilita el desarrollo de una política económica anticíclica, de modo que ambos niveles de gobierno puedan endeudarse en épocas de menor crecimiento, debiendo adoptarse medidas de ahorro y amortización de las deudas en fases de expansión, que lleven a un presupuesto equilibrado a largo plazo ${ }^{61}$.

En el caso del Bund, el artículo 115.2 (quinta frase) se remite a una Ley Federal que desarrolle el procedimiento para la cuantificación del límite máximo de déficit coyuntural anual. La Ley de 10 de agosto de 2009, de desarrollo del artículo 115 GG, (G115) concreta, en este sentido, cuándo se produce una divergencia del desarrollo económico respecto de la situación normal ( $\$ 5.2)$, remitiendo a su vez al desarrollo reglamentario el procedimiento para el cálculo de la cifra de endeudamiento coyuntural permitida para cada ejercicio ${ }^{62}$.

- 3. La Constitución contempla límites más estrictos al endeudamiento estructural. El endeudamiento estructural existe cuando se contrae crédito para financiar gastos públicos que, incluso en una coyuntura económica ordinaria, no cuentan con financiación suficiente de los ingresos regulares del Estado por tributos o ingresos patrimoniales. A través de este endeudamiento no se trata, en consecuencia, de lograr una financiación transitoria, sino de la existencia de una permanente descompensación entre los ingresos y los gastos $^{63}$.

a) En relación con Bund, los artículos 109.3 y 115.2 GG señalan que el principio de nulo endeudamiento se entenderá cumplido cuando exista un endeudamiento de un máximo del 0,35\% del PIB. El Bund tiene, por tanto, la posibilidad de mantener un endeudamiento estructural hasta este límite, con independencia de la coyuntura económica concreta.

Algunos autores han querido ver en este componente del déficit una vinculación con el gasto por inversiones ${ }^{64}$. De los debates habidos durante la reforma se desprende, sin embargo, la intención de desarrollar un concepto diverso al de la regulación anterior, dotado de «mayor flexibilidad interna», sin vinculación al concepto de las inversio-

60 Cfr. W. HÖFLING, Staatsschuldenrecht. Rechtsgrundlagen und Rechtsmasstäbe für die Staatsschuldenpolitk in der Bundesrepublik Deutschland, Heidelberg, 1993, pag. 251.

61 Cfr. E. REIMER, Art. 109, ob.cit. Rn. 59, 72 y 73.

62 BGB1. I S. 2702 (2704).

63 Cfr. U. WOLF, Verfassungsrechtliche Grenzen der Staatsverschuldung in der Bundesrepublik Deutschland: Die Bedeutung des Ar. 115 GG im Rabmen der von Art. 109. Abs. 2 GG verankerten gesamtwirtschaftlichen Funktion des Haushalts, Hamburg, 1984, pág. 124.

64 C. SEILER, »Konsolidierung der Staatsfinanzen mithilfe der neuen Schuldenregel«, ob.cit., pág. 723. 
nes ${ }^{65}$. En todo caso, el componente estructural, tal y como se encuentra ahora recogido en la Constitución, queda por debajo del nivel de gasto por inversiones existente hasta el momento, tanto del concepto de inversiones brutas como netas, que tras la entrada en vigor de la nueva regulación constitucional, habrán de financiarse a través de ingresos no crediticios $^{66}$. Por otra parte, y a diferencia de lo que ocurre para el endeudamiento coyuntural, no se prevé en este supuesto ningún deber correlativo de amortización, lo que puede propiciar la acumulación de deuda, aunque condicionada en todo caso por el límite comunitario del $60 \%$ del PIB.

b) A los Länder, sin embargo, se les cierra totalmente la capacidad de contraer endeudamiento estructural. Las repercusiones de esta norma para sus finanzas obligan, como luego veremos, a establecer un largo período de carencia hasta su entrada en vigor y a proveerles transitoriamente de ayudas financieras para ir equilibrando su situación financiera.

- 4. La Constitución permite, por otra parte, tanto al Bund como a los Länder (artículos 109.3 y 115.2 GG), superar los límites previstos con anterioridad si concurre una situación de catástrofe natural u otra situación excepcional de carácter extraordinario. Con ello se pretende mantener la capacidad de actuación del Estado ante acontecimientos que, según el tenor literal de la Constitución, «escapen al control del Estado y perjudiquen considerablemente la situación financiera estatal». Para ello es necesario, en el caso del Bund, un acuerdo de la mayoría del Bundestag. Este acuerdo debe estar provisto de un plan de amortización, de manera que los créditos sean devueltos en un «plazo razonable». Al preverse esta excepción se observa la orientación de la nueva limitación constitucional a las normas comunitarias restrictivas del déficit. El artículo 2.1 del Reglamento 1467/97 del Consejo recoge una formulación semejante como excepción a la aplicación de los márgenes de déficit establecidos.

Sobre esta excepción se ha criticado que no se hubiera introducido de forma expresa una afectación de los recursos obtenidos a través del crédito a esta finalidad, ni que se hubiera limitado de algún modo su cuantía en función de la situación producida, aunque dicha vinculación puede desprenderse, al decir de otros autores, de la propia finalidad de la norma ${ }^{67}$.

- 5. En relación con el Bund, se obliga a incorporar a una cuenta de control las divergencias que se produzcan entre el endeudamiento efectivamente contraído y los límites fijados al mismo, para proceder a su compensación. Con ello se trata de asegurar que estos límites operan también en fase de ejecución presupuestaria. Los cargos en dicha cuenta que superen el 1,5\% del PIB habrán de reducirse «de acuerdo con la coyuntura», de donde se desprende que sólo en los años de crecimiento económico se llevará a cabo la reducción. Si el estado de la cuenta alcanza el 1\% del PIB, la Ley de Desarrollo del artículo 115 ( $\$ 7.2$ G 115) prevé, no obstante, que el límite al endeudamiento estructural del

65 Beschlusse der Kommission von Bundestag und Bundesrat zur Modernisierung der Bund-Länder-Finanzbeziebungen, Kommissionsdrucksache 174 der FöKo II, s. 10.

66 Cfr. SACHVERSTÄNDIGENRAT ZUR BEGUTACHTUNG DER GESAMTWIRTSCHAFTLICHEN ENTWICKLUNG (Hrsg.) Staatverschuldung wirksam begrenzen ..., ob.cit., pág. 179.

67 Cfr. M. THYRE, Die neue «Schuldenbremse» im Grundgesetz, Universtätsverlag Halle-Wittenberg, 2010, pág. 32. 
0,35\% del PIB se reduzca hasta eliminar la cuantía excedente de la cuenta de control. Esta limitación sólo es aplicable, igualmente en los años de coyuntura económica positiva.

- 6. En el artículo $143 \mathrm{~d}$ se recogen, por otra parte, una serie de disposiciones transitorias que difieren la aplicación a los Länder de los nuevos límites hasta el 31 de diciembre de 2019, aplicando entretanto las normas vigentes en sus Constituciones. A partir del año 2020 ya no podrán, sin embargo, contraer endeudamiento estructural. También para el Bund, la entrada en vigor del límite del 0,35\% del PIB para este tipo de déficit se difiere hasta el 1 de enero de 2016.

Durante el período de 2011 a 2019 se prevé, además, la concesión a los Länder con mayores problemas financieros de «ayudas de consolidación», cuyo reparto se contempla específicamente en la Constitución. La concesión de estas ayudas está condicionada a la total reducción del déficit de financiación hasta el fin de 2020. Los detalles sobre su concesión, administración y control se remiten a una Ley federal con la aprobación del Bundesrat. La carga financiera de su concesión se reparte, por otro lado, entre la Federación y los Estados, cuya aportación se detrae de su participación en el IVA.

- 7. Los límites de los artículos 109 y 115 deben interpretarse, en todo caso, a la luz de las normas comunitarias que, además de un límite añadido para la deuda acumulada, contemplan un margen máximo de déficit total del 3\% del PIB, aunque con una gran flexibilidad en cuanto a su cómputo y numerosas excepciones a su aplicación en función de los condicionantes socio-económicos de cada país. Los preceptos constitucionales implican, en todo caso, el reparto interno de las cuantías máximas de déficit entre la Federación y los Estados, aspecto no regulado por las normas comunitarias, a la vista de la autonomía institucional y procedimental que se reconoce a los Estados miembros.

\subsection{Valoración del contenido material de la nueva regulación}

En la valoración jurídica del nuevo límite constitucional se han destacado diversos aspectos positivos. En primer término, la certidumbre y concreción de su contenido, que favorecerá su efectividad y reducirá los problemas de interpretación planteados por la norma anterior. Aunque la Constitución no ofrezca las líneas generales para determinar el límite máximo de endeudamiento coyuntural, la remisión a otras normas para el desarrollo de esta fórmula, se considera un avance respecto de la situación anterior ${ }^{68}$. Pueden plantearse problemas, no obstante, en la concreción de las circunstancias concurrentes para entender que la coyuntura económica diverge de la ordinaria, para lo que será necesario partir de un valor medio y realista que evite realizar previsiones erróneas que puedan favorecer el endeudamiento ${ }^{69}$.

En general, se considera, por otra parte, que las situaciones excepcionales que permiten la superación de los límites ordinarios aparecen correctamente identificadas en la Constitución, debiendo dejarse esta cláusula deliberadamente abierta para mantener la capacidad de actuación del Estado ${ }^{70}$ Hubiera sido deseable, en cambio, una mayor concre-

68 Cfr. C. RYCZEWSKI, Die Schuldbremse im Grundgesetz, ob.cit, págs. 179 y ss.

69 Idem.

70 Cfr. C. SEILER, »Konsolidierung der Staatsfinanzen mithilfe der neuen Schuldenregel«, ob.cit., pág. 726. 
ción sobre el plazo «razonable» en el que llevar a cabo la amortización de la deuda contraída en estos supuestos ${ }^{71}$. También se considera un acierto la supresión de la posibilidad de acudir a la dotación de patrimonios especiales para ampliar los límites al endeudamiento $^{72}$ y el que la Constitución haya recogido el deber de evitar comportamientos procíclicos. De ella se desprende, en efecto, el deber de reducir la deuda en fases de expansión, al establecerse el principio de estabilidad presupuestaria y aludirse a la simétrica toma en consideración de las fases de expansión y contracción de la economía para fijar el nivel de endeudamiento admisible ${ }^{73}$.

Se ha criticado, sin embargo, la formulación de la regla relativa al déficit estructural, que al permitir sin mayores requisitos alcanzar el déficit del 0,35 del PIB puede propiciar la acumulación de deuda incluso en fases de expansión económica ${ }^{74}$. Del mismo modo, tampoco la nueva norma ha planteado soluciones alternativas que faciliten el control de constitucionalidad de las leyes de presupuestos en el cumplimiento de estos límites, legitimando, por ejemplo, al Tribunal de Cuentas $^{75}$ o a una parte más reducida del Bundestag para recurrir su incumplimiento ${ }^{76}$.

También desde la perspectiva del control de constitucionalidad, se ha planteado la necesidad de introducir alguna sanción constructiva ante la vulneración de los límites previstos. Con la declaración de inconstitucionalidad de la Ley de Presupuestos no se elimina la deuda contraída ni se abarcan los déficits aparecidos en fase de ejecución presupuestaria. Ciertamente, la nueva regulación constitucional contempla dos instrumentos tendentes a reducir los déficits excesivos: la creación de una cuenta de control y del denominado Consejo de Estabilidad. La primera tiene por finalidad, según señalamos con anterioridad, abarcar también los déficits que se producen en fase de ejecución presupuestaria, que deberán llevarse a dicha cuenta. Se establece, en contrapartida, un deber de amortizar las cargas que se vayan anotando, aunque de forma muy indeterminada, lo que reducirá su efectividad. No existe, en efecto, obligación de reducir la deuda contraída hasta que la acumulada en la cuenta de control no supere el 1,5\% del PIB. Tampoco se contempla un plazo determinado para proceder a la amortización. Se señala tan sólo que las cantidades llevadas a la cuenta «deben reducirse de forma adecuada a la coyuntura», lo que sólo tiene un efecto limitador negativo, en el sentido de que en épocas de recesión no es necesario llevar a cabo la amortización. La Ley de desarrollo del artículo 115 de la Constitución no señala, sin embargo, en qué medida debe procederse a la amortización en las épocas de crecimiento económico ${ }^{77}$.

71 Se ha propuesto, por ejemplo, el establecimiento en la Ley de un plazo general de cinco años para proceder a la amortización, salvo situaciones excepcionales. Cfr. C. SEILER, »Konsolidierung der Staatsfinanzen mithilfe der neuen Schuldenregel«, ob.cit., pág. 726.

72 Cfr. C. RYCZEWSKI, Die Schuldbremse im Grundgesetz, ob.cit, págs. 185.

73 Cfr. E. REIMER, Art. 109, ob.cit., Rn. 5 pág. 40.

74 Cfr. C. RYCZEWSKI, que destaca que la formulación de esta norma volverá a permitir su «automatismo» en la misma línea del límite anterior. Die Schuldbremse im Grundgesetz, ob.cit., págs. 181 y ss.

75 Esta posibilidad se había formulado ya al hilo de la anterior regulación. Vid. entre otros, V. ARNIM, «Grundprobleme der Finanzkontrolle», Deutsches Verwaltungsblatt (DVBl) 1983, pág. 668.

76 Cfr. SACHVERTÄNDIGENRAT ZUR BEGUTACHTUNG DER GESAMTWIRTSCHAFTLICHEN ENTWICKLUNG (Hrsg.) Staatverschuldung wirksam begrenzen, ob.cit., pá. 113.

77 Cfr. C. RYCZEWSKI, Die Schuldbremse im Grundgesetz, ob.cit., págs.. 187. 
Como segunda medida, se crea también el Consejo de Estabilidad (Stabilitätsrat), entre cuyas funciones se encuentra, según se desprende del artículo 109a, la vigilancia de la gestión presupuestaria federal y estatal. Este órgano está compuesto por el Ministro Federal de Economía y Tecnología y por representantes de ambas instancias territoriales. En el marco de esta «vigilancia presupuestaria», el consejo fija unos límites cuya superación obliga a realizar una «advertencia» al ente afectado y a adoptar un acuerdo para implantar un programa de saneamiento de sus cuentas, aunque como advierte KORIOTH, el consejo carezca de competencia para su implantación obligatoria ${ }^{78}$.

Como sanción complementaria, se ha propuesto la introducción en la Constitución de la obligatoriedad de implantar un recargo variable sobre el Impuesto sobre la Renta cuando se incumplan los límites establecidos, que permita la compensación del exceso de déficit de los ejercicios anteriores. Con ello se trataría de hacer visible la situación producida, repercutiendo sobre los responsables públicos el coste político de sus decisiones de gasto $^{79}$.

\subsection{OTROS ASPECTOS CONFLICTIVOS. VULNERACIÓN DE LOS PRINCIPIOS FEDERAL Y DEMOCRÁTICO. RANGO CONSTITUCIONAL DEL LÍMITE AL ENDEUDAMIENTO.}

Al igual que ocurrió en nuestro país con las normas sobre la estabilidad presupuestaria y el principio de autonomía financiera, la introducción en la Constitución alemana de un límite al endeudamiento de los Länder planteó dudas sobre su compatibilidad con el principio federal previsto en el artículo 79. 3 de la Constitución. Esta norma declara inadmisibles las reformas constitucionales que alteren la división de la Federación en Estados. Es lo que se denomina la «garantía perpetua» del carácter federal del Estado, que impide el vaciamiento del carácter estatal de los Länder a través de reformas constitucionales que eliminen progresivamente sus competencias ${ }^{80}$.

Desde el punto de vista de la actividad financiera, el carácter federal del Estado, implica la garantía constitucional de dotar a los Länder de una parte de los ingresos tributarios adecuada a sus competencias. Los Länder deben contar también con su propio presupuesto (autonomía presupuestaria formal) y desarrollar a través del mismo su iniciativa política (autonomía presupuestaria material) ${ }^{81}$. Se plantea, en consecuencia, si la prohibición de endeudamiento estructural impide a los Länder el adecuado ejercicio

78 Cfr. S. KORIOTH, «Das neue Staatschuldenrecht _zur zweiten Stufe der Förderalismusreform», ob.cit., pág. 735 .

79 A favor de la introducción de este recargo, vid., entre otros, S. KORIOTH, «Das neue Staatschuldenrecht_zur zweiten Stufe der Förderalismusreform», pág. 735 y C. RYCZEWSKI, Die Schuldbremse im Grundgesetz, ob.cit, págs 199 y ss.

80 Esta peculiaridad de la Constitución alemana se explica a partir de los acontecimientos históricos producidos tras la República de Weimar, cuando se eliminaron los Länder y se transmitieron todas sus competencias al Reich, lo que permitió la concentración total del poder en Hitler. Vid. sobre la justificación y significado actual de este principio, C. RYCZEWSKI, Die Schuldbremse im Grundgesetz, ob.cit, pág. 157.

81 Cfr. Las Sentencias de 26 de julio de 1972, 24 de junio de 1986 y 26 de julio de 1992. BVerFG Urt. De 26.07.1972, _ 2 BvF 1/71, BVerfGE 34, 9 (19 f.); (BVerfG. Urt. De 24. 06.1986-2 BvF 1, 5, 6/83, 1/84 y 2/85, BVerfGE 72330 (383) y BVerfG, Urt. de26.07.1992-2BvF 1/7, BVerfGE 34, 9 (20). 
de sus competencias, mermando su condición «estatal» y resultando, por ello, contraria a la Constitución.

Quienes defienden esta tesis parten de la tradición constitucional alemana, al considerar que la ausencia de limitaciones al endeudamiento en la primera versión de la Ley Fundamental era una expresión del concepto originario de Estado en esta norma y, con ello, una concreción del principio federal ${ }^{82}$. Se añade, también que la autonomía presupuestaria de los Länder, como expresión del principio federal, sólo puede limitarse en la medida en sea necesaria para el cumplimiento de sus funciones, considerando que el establecimiento de un límite permanente y vinculante a estos efectos resulta incompatible con el citado principio $^{83}$. Se alude así mismo, a la relevancia cualitativa de los ingresos crediticios para hacer efectiva la autonomía presupuestaria de los Estados, pues apenas pueden decidir sobre la cuantía de sus ingresos tributarios, más allá de su participación colectiva a través del Bundesrat en la aprobación de las Leyes Federales ${ }^{84}$.

Otros autores destacan, sin embargo, que la autonomía financiera no implica total disponibilidad para endeudarse sino, de acuerdo con la jurisprudencia del Tribunal Constitucional, la adecuada dotación financiera de recursos para el cumplimiento de sus funciones, que puede obtenerse por otras vías distintas del endeudamiento, debate que queda, no obstante, abierto tras la reforma constitucional ${ }^{85}$.

En contra de la vulneración de este principio se ha señalado, por otra parte, que la existencia de limitaciones al ejercicio de la autonomía financiera constituye una restricción inherente al carácter compuesto de la Federación, del que se derivan multitud de derechos pero también deberes que inciden sobre la soberanía de los entes que la integran. Como advierte RYCZEWSKI el apoyo de la Federación en situaciones de insuficiencia financiera, exige una correlativa cooperación y disciplina presupuestaria por parte de los Länder, para evitar que el excesivo endeudamiento perjudique al Estado en su conjunto. Por otra parte la limitación a la soberanía popular contenida en el artículo 79.3 exige ser interpretada restrictivamente, sin impedir reformas parciales de la organización territorial del Estado cuando existan motivos justificados, como ocurre en este caso, para asegurar la sostenibilidad de las finanzas públicas, mantener la capacidad de actuación del Estado, favorecer la justicia intergeneracional y contribuir al cumplimiento de las obligaciones comunitarias en el marco del Pacto de estabilidad y crecimiento ${ }^{86}$.

A favor de la adecuación de la reforma al principio federal se ha destacado también la inexistencia de una prohibición absoluta al endeudamiento de los Länder, que pueden utilizar el componente de endeudamiento coyuntural para recurrir al crédito en épocas de desaceleración económica, cuando mayor es la necesidad financiera de equi-

82 Cfr. J. HANCKE, Defizitbegrenzung im Bundestaat; Grundgesetzliche Vorgaben einer verbindlichen Vershculdungsregel, Göttingen, 2008, pág. 156 y ss.

83 Idem.

84 Cfr. S.KORIOTH, «Das neue Staatschuldenrecht_zur zweiten Stufe der Förderalismusreform», JZ, 2009, pág. 732.

85 Cfr. C. RYCZEWSKI, Die Schuldbremse im Grundgesetz, ob.cit, pág. 163

86 Cfr. C. RYCZEWSKI, que destaca también la tradición unitaria del federalismo alemán. Die Schuldbremse im Grundgesetz, ob.cit, págs. 153 y 163. 
librar el presupuesto, o endeudarse ante acontecimientos extraordinarios, según la excepción prevista en el artículo $109.3^{87}$.

La nueva regulación se ha cuestionado, en segundo término, desde el punto de vista del principio democrático recogido en el artículo 20.1 de la Constitución y dotado también de la protección constitucional reforzada del artículo 79.3. Se ha planteado, en efecto, si la limitación al endeudamiento supone un desapoderamiento de las competencias presupuestarias de los Parlamentos de los Länder ${ }^{88}$. Las críticas se acentúan si se tienen en cuenta que la participación de los Länder en la reforma constitucional se lleva a cabo a través del Bundesrat y no de los parlamentos regionales. En contra de esta tesis se ha destacado, sin embargo, que la introducción de este límite no supone la sustracción de sus competencias presupuestarias sino de una limitación parcial a su capacidad de actuación para la obtención de ingresos, que trata de garantizar, además, los derechos democráticos de las generaciones futuras, para evitar que el elevado endeudamiento limite su capacidad de decisión política ${ }^{89}$.

Otro de los aspectos conflictivos de la nueva regulación fue el rango constitucional que se le otorgó, por considerar que se trataba de una regulación técnica y prolija, impropia de una norma de este carácter, más proclive a la inclusión de principios y normas de carácter general ${ }^{90}$. El contenido de esta norma viene condicionado, sin duda, por la experiencia existente en la aplicación del anterior límite al endeudamiento, cuya indeterminación había favorecido su ineficacia, estando en consonancia, además, con el tecnicismo que caracteriza otros preceptos de la Constitución Financiera. Por otra parte, al no existir en Alemania una norma de rango equivalente a la Ley orgánica, el límite ha de ser necesariamente constitucional, para gozar de efecto vinculante sobre las Leyes de presupuestos posteriores $^{91}$.

Finalmente, existen también otros aspectos mejorables en la redacción de la norma. Se trata de aspectos formales como la reiteración de las reglas relativas a la Federación en los artículos 109 y 115, cuya lectura induce a confusión o la incorporación de una referencia expresa al artículo 104 del Tratado de la Unión Europea que, tras la reforma constitucional fue sustituido por el Tratado de Funcionamiento de la Unión Europea. Esta remisión podría haberse sustituido por una más general a las obligaciones de disciplina presupuestaria en el marco de la Unión Europea, para propiciar una interpretación dinámica del precepto $^{92}$.

87 Ibidem, pág. 150.

88 Vid. en este sentido, SCHNEIDER, Schuldenregeln des Bundes für die Haushaltwirtschaft der Länder, Documento núm. 134 de la Comisión del Federalismo II, página 27. Así como la Carta abierta de los representantes de los Parlamentos Regionales sobre esta materia. Documento núm. 100 de la misma Comisión.

89 Cfr. C. RYCZEWSKI, Die Schuldbremse im Grundgesetz, ob.cit, pág. 166.

90 Entre otros, vid, en este sentido P.SELMER, que considera que la Constitución debería haberse limitado a establecer el principio de presupuesto equilibrado «Die Förderalimusreform II - Ein verfassungsrechtliches monstrum simile, Neue Zeitschrift für Verwaltungsrecht (NVwZ) 2009, pág. 1259 y S. KORIOTH, «Das neue Staatschuldenrecht_zur zweiten Stufe der Förderalismusreform», ob.cit, pág. 737.

91 C. RYCZEWSKI, Die Schuldbremse im Grundgesetz, ob.cit. págs. 173-174.

92 Vid. ambas críticas en C. RYCZEWSKI, Die Schuldbremse im Grundgesetz, ob.cit, págs. 177 y 178. 


\section{OtRos ASPECTOS DISCUTIDOS EN EL PROCESO DE REFORMA CONSTITUCIONAL}

\subsection{La centralización de la Administración tributaria}

La Constitución financiera alemana opta, como señalamos con anterioridad, por un modelo descentralizado de Administración tributaria, donde las competencias para la aplicación de los tributos más relevantes del sistema recaen sobre los Länder, que transfieren una parte de las cantidades recaudadas a la Federación, tratándose de tributos compartidos. Las debilidades de este modelo han sido puestas de manifiesto desde hace tiempo desde distintos ámbitos políticos y académicos. El Tribunal de Cuentas Alemán ha afirmado en diversos informes que la organización administrativa vigente no garantiza la correcta e igualitaria ejecución de las normas tributarias ${ }^{93}$. Tales informes destacan, en efecto, la insuficiente persecución del fraude fiscal, la lentitud en el desarrollo de los procedimientos tributarios, el uso de prácticas de liquidación e inspección distintas, la utilización de software diversos para la aplicación de los tributos y la preferencia de los intereses particulares del Land en el desempeño de sus funciones en perjuicio de otros de carácter general ${ }^{94}$.

Se ha señalado, además, que el sistema de compensación financiera interterritorial existente en Alemania desincentiva la eficacia de las Administraciones Tributarias de los Estados implicados: las de los que contribuyen a la nivelación, porque buena parte del incremento recaudatorio que pudieran obtener iría a parar a otros Estados, y las de los beneficiarios de las transferencias, ya que cualquier aumento de sus ingresos tiene por efecto la reducción de su cuantía95.

Con la finalidad de superar estas deficiencias, la I Reforma del Federalismo intentó mejorar la coordinación existente entre las distintas Administraciones territoriales, reforzando la capacidad de dirección y control de la Federación respecto de la administración delegada de los tributos compartidos. La Ley de acompañamiento de la reforma del

93 Cfr. Bemerkungen des Bundesrechnungshofes 2005 zur Haushaltsnd Wirtchaftsführung des Bundes, Nr. 3.2.1, BT-Drs. 16/160, págs. 102 y ss.

94 Especialmente graves son las consideraciones realizadas sobre la relajación de las potestades de comprobación o la aplicación de criterios interpretativos favorables al contribuyente con la finalidad de atraer inversiones hacia el territorio de cada Estado o favorecer a las empresas en él asentadas. Ibidem, págs. 63-64. Vid. además del citado en la nota anterior, el informe de su presidente, D. ENGELS, Modernisierung der Verwaltungsbeziehungen von Bund und Länder. Gutache des Präsiden des Bundesrechnungshofes als Bundesbeauftragter für Wirtschaflichkeit in der Verwaltung, Bonn, 27 september 2007. Vid. También, entre la doctrina, poniendo también de manifiesto las deficiencias de este modelo, A. DITTMANN, »Gleichheitssatz und Gesetzesvollzug im Bundesstaat «, FS Düring, 1990, págs. 221 y ss, H. VOGEL, Ungleichbeiten beim Vollzug von Steuergesetzen im bundesstaat. Juristische und ökonomische Analyse, Diss. Hohenheim, 2000.

95 Vid. sobre este particular, en el marco de los trabajos de la Comisión sobre la reforma de las relaciones financieras, S. KORIOTH, Stellungnahme zur öffentlichen Anbörung der Kommision ..., ob.cit., págs. 19 y 20 y K. A. KONRAD, Stellungnabme zur öffentlichen Anbörung der Kommision..., ob.cit., págs. 24 y 25. Aunque como advierte DRÜEN, resulta difícil imaginar que el actuario que desarrolla los procedimientos de comprobación e investigación se vea influenciado por tales consideraciones, sí puede faltar, en cambio, la voluntad política de realizar una adecuada dotación de medios personales y materiales para la comprobación, cuya financiación corresponde, por otra parte, a los Gobiernos de los Länder Cfr. «Konzernbetriebsprüfung im föderalen Steuerstaat», Steuern und Wirtschaft (StuW) 2/2007, pág. 118. 
federalismo (Förderalismusreform-Beleitgesetz, de 5 de septiembre de 2006) introdujo al efecto, diversas medidas en la Ley de la Administración Financiera (Finanzverwaltungsgesetz), como la posibilidad de que la Federación, a través de la Oficina Central Federal, dicte directrices generales en materia de inspección, participe en la persecución de delitos contra a la Hacienda Pública de alcance nacional o internacional, mediante una función de apoyo e información a las Administraciones de los Länder, así como la introducción de programas informáticos unificados para la aplicación de los tributos siempre que no exista oposición por parte de la mayoría de los Länder y dejando, además, a éstos últimos su desarrollo técnico.

La conveniencia de ir más allá, transfiriendo directamente a la Federación la aplicación de los tributos compartidos fue objeto de debate en la Comisión para la revisión de la Constitución Financiera de 2009. Esta Comisión dedicó su segunda fase a la revisión general de la distribución de competencias administrativas entre el Bund y los Länder, partiendo de la constatación de que la coordinación y compleja distribución de tareas entre ambos niveles territoriales induce a confusión y conlleva costes materiales y temporales que era necesario reducir. Como resultado de estos debates se reformaron diversos preceptos de la Constitución para uniformar el actuar administrativo mediante el uso de sistemas unitarios de tratamiento de la información que faciliten la colaboración y el intercambio de datos dentro de la Administración y con los ciudadanos ${ }^{96}$.

Dentro de este marco general, la Comisión trató particularmente la necesidad de reformar la Administración tributaria. La opción impulsada desde el Ministerio de Finanzas, el Tribunal de Cuentas y algunos partidos políticos integrantes de la misma fue la de centralizar en manos federales la administración de los impuestos compartidos. Además de los informes del Tribunal de Cuentas antes referidos, la Comisión manejó el denominado Informe «Kimbaum», encargado por el Ministerio Federal de Finanzas a una consultora independiente, al objeto de cuantificar la menor recaudación y pérdida de eficiencia «derivados de la estructura federal de la Administración tributaria y su previsible incremento de existir una única Administración federal de los impuestos compartidos». Entre otras conclusiones, el informe consideró que la Administración centralizada de todos los impuestos de regulación federal unitaria, los compartidos e incluso aquellos cuyo rendimiento corresponde a los Länder, con posterior transferencia de lo recaudado, era el modelo más eficiente. El informe estimaba que el incremento recaudatorio y el ahorro de costes que implicaría su implantación ascendería a 11.500 millones de euros en diez años, amén de otras ventajas para los contribuyentes, al simplificarse el cumplimiento de las obligaciones y deberes tributarios ${ }^{97}$.

A pesar de la evidencia de este estudio, la iniciativa impulsada por el Ministerio Federal de finanzas y apoyada por algunos partidos políticos fue rechazada por los Länder, li-

96 Sobre las modificaciones introducidas en este terreno, vid. A. ARROYO GIL, «La refoma constitucional de 2009 de las relaciones financieras entre la Federación y los Länder en la República Federal de Alemania», ob.cit, págs. 63 y ss.

97 Abschlussbericht "Quantifizierung der im Falle einer Bundessteuerverwaltung bzw. Einer verbesserten Kooperation, Koordination und Organisation der Läderverwaltung zu erwartenden Effizienzgewinne ", Berlin 28 de Diciembre de 2006. Llega también a la misma conclusión el informe presentado por KPMG, Reformmodelle der Steuerverwaltung. Stellungnabme zum Fragenkatalog für die öffentliche Anbörung am 8 November 2007. 
mitándose la Comisión a la introducción de nuevas medidas en la Legislación ordinaria tendentes a favorecer la coordinación entre las Administraciones tributarias Federal y estatal, en la línea de las reformas ya efectuadas en 2006.

\subsection{El incremento de la autonomía tributaria de los Länder}

Ante la limitación del recurso al crédito por parte de los Länder, los trabajos de la Comisión se centraron también en analizar posibles propuestas para reordenar sus competencias tributarias. En los debates desarrollados, una parte importante de sus miembros era partidario de la concesión a estos entes de competencias normativas exclusivas sobre los impuestos cuya recaudación íntegra les corresponde, salvo en relación con el impuesto sobre sucesiones y donaciones. Nada habría que objetar, en efecto, a la existencia de regímenes diversos en el impuesto sobre vehículos a motor o en el gravamen de las loterías, por ejemplo ${ }^{98}$. Respecto al impuesto sobre sucesiones y donaciones, la necesidad de mantener criterios unitarios en la valoración de los bienes y el temor ante la incidencia de la competencia fiscal sobre la estructura y finalidad de este tributo, llevó en cambio a defender su regulación unitaria. La competencia fiscal interna se valoró en este sentido más perjudicial que la que pudiera ejercerse desde el exterior, ante la movilidad de la residencia y el patrimonio dentro del país ${ }^{99}$.

El mismo argumento se utilizó para rechazar la concesión a los Länder de recargos sobre los impuestos sobre la renta y sociedades ${ }^{100}$.

En esta discusión se enfrentaron, en definitiva, diversas concepciones del federalismo alemán. Para los partidarios del denominado «federalismo competitivo», la creación de condiciones de vida igualitarias en todo el territorio federal a la que aluden los artículos 106.3 Nr. 2 y 74.2 de la Constitución no era consustancial al modelo federal alemán, destacando los efectos positivos de la competencia fiscal para la economía y la eficiencia de las prestaciones públicas ${ }^{101}$. Frente a ella se destacó la relevancia del principio de solidaridad como un valor inherente a la condición federal del Estado, dotado de igual protección frente a una hipotetica reforma constitucional, en los términos del artículo 79.3 de la Constitución ${ }^{102}$. Los partidarios de esta tesis destacaron las escasa capacidad de decisión real de la que disponías los Estados más pobres que, con ingresos tributarios muy por debajo de la media nacional y buena parte de sus gastos comprometidos a nivel federal, apenas podrían reaccionar ante la rebaja de tipos de gravamen que iniciaran los

98 Cfr. S. KORIOTH Stellungnabme zur öffentlichen Anhörung der Kommision ..., ob.cit., págs. 13 y ss y H. MEYER, Stellungnahme zum Fragenkatalog der Föderalismuskommission II ob.cit., págs. 21 y ss.

99 Rechazando también la transferencia de competencias legislativas sobre este impuesto a los Estados ante el temor a la competencia fiscal, vid. K. A. KONRAD, Stellungnabme zur öffentlichen Anbörung der Kommision ..., ob.cit., págs. 26 y 27. y T. LENK Stellungnahme zum Fragenkatalog der Föderalismuskommission II, págs. 24-25.

100 Cfr. este argumento en la toma de postura de J. WIELAND en la citada Comisión. Schriftliche Stellungnabme für die öffentliche Anbörung am 22. Juni 2007, págs. 1 y 2.

101 Cfr. L. P. FELD, Schriftliche Stellungnabme für die Anbörung der Föderalismuskommission II zu den Finanzthemen am 22. juni 2007, pág. 33 y ss.

102 Cfr. L. P. WIELAND, Schriftliche Stellungnabme für die öffentliche Anbörung am 22. juni 2007, págs. 1 y ss. 
territorios mejor dotados ${ }^{103}$. Precisamente con este fundamento, en el marco del fallido intento de reforma constitucional de 2004, los Gobiernos de los Länder convivieron la renuncia a ampliar sus competencias tributarias ${ }^{104}$.

\section{CONSIDERACIONES FINALES: PERSPECTIVAS PARA ESPAÑA}

El modelo de reparto territorial de competencias financieras en la Ley Fundamental de Bonn presenta notables diferencias con el existente en nuestro país entre el Estado y las Comunidades Autónomas.

La Constitución Española no impuso, como advierte TEJERIZO LÓPEZ, ningún modelo específico de financiación autonómica, «lo que ha propiciado que los modelos sucesivamente vigentes hayan vivido en un estado de crisis permanente» ${ }^{105}$. El artículo 156 de la Constitución reconoce la autonomía financiera de las Comunidades Autónomas, principio que se completa con la enumeración en el artículo 157 de los recursos de los que podrán disponer. Entre ellos, se prevé que puedan establecer sus propios tributos y exigir otros cedidos por el Estado. Dicha norma se remite por lo demás, a una Ley Orgánica para el desarrollo de sus competencias financieras, en la actualidad, la Ley 8/1980, Orgánica de Financiación de las Comunidades Autónomas, de 22 de septiembre (LOFCA).

Diversos factores explican, desde nuestro punto de vista, la parquedad de las normas constitucionales españolas en la definición de las relaciones financieras interterritoriales, en comparación con el modelo alemán. Entre ellas destacan, además del papel de las Leyes Orgánicas como fuentes del Derecho, inexistentes en el Derecho alemán, el origen constitucional del Estado autonómico, su carácter abierto en el texto constitucional y su formación posterior, mediante la progresiva asunción de competencias por parte de las Comunidades Autónomas. A ello se une también el tardío origen de nuestro actual sistema tributario, vinculado también a la Constitución y su desarrollo de forma escalonada durante la década siguiente a su aprobación, lo que impedía recoger ya en el texto constitucional y al modo de los artículos 105 y 106 de la Ley Fundamental de Bonn, un reparto detallado de los impuestos entre los distintos niveles territoriales, aspecto desarrollado por la LOFCA en nuestro país.

La indefinición del modelo de relaciones financieras territoriales en la Constitución Española ha propiciado, en todo caso, que esta regulación haya permanecido inalterada desde su aprobación. El debate y la modificación de los sucesivos modelos de financiación se han desplazado, en efecto, a la Ley Orgánica de Financiación de las Comunidades Autónomas y a sus Leyes de desarrollo. A la vista de las reformas efectuadas y del desarrollo del Estado autonómico alcanzado, habría de valorarse la reforma constitucional de

103 Cfr. J. WIELAND, Schriftliche Stellungnabme für die öffentliche Anbörung am 22. Juni 2007, págs. 11 y ss. Advierten también del peligro de la competencia fiscal en relación con estos impuestos distintos informes presentados a la Comisión. Vid. los de K. A. KONRAD, Stellungnabme zur öffentlichen Anbörung der Kommision ..., ob.cit., págs. 26 y 27, T. LENK Stellungnahme zum Fragenkatalog der Föderalismuskommission II e I.

104 Vid. Föderalismusreform-Positionpapier der Ministerpräsidents, (Documento de la Comisión núm. 45), 14.05.2004, págs. 3 y ss.

105 Cfr. TEJERIZO LÓPEZ, La financiación territorial en los Estados descentralizados... Ob. cit. pág 135. 
los preceptos relativos a la financiación autonómica, concretando algunos de los principios constitucionales allí previstos, con la finalidad de dotar de estabilidad al reparto territorial de competencias financieras.

El modelo español se caracteriza, por otra parte, por la rápida y profunda descentralización alcanzada en la atribución de competencias tributarias a las Comunidades Autónomas. A diferencia de lo que ocurre en Alemania, las Comunidades Autónomas pueden establecer sus propios impuestos, si bien las prohibiciones de doble imposición existentes en relación con el sistema tributario estatal y local, han limitado en la práctica esta fuente de recursos. A este respecto, la Constitución, además de recoger el principio de coordinación con la Hacienda estatal, tan sólo señala que las medidas tributarias autonómicas no podrán gravar bienes situados fuera de su territorio o suponer un obstáculo para la libre circulación de mercancías y servicios. La Ley Orgánica de Financiación de las Comunidades Autónomas prohibió, sin embargo, en su artículo 6. 2 y 3 gravar los hechos imponibles ya gravados por el Estado, además de impedir que sus tributos recayeran sobre las materias imponibles reservadas por la Legislación de Régimen Local a las Comunidades Autónomas. La jurisprudencia del Tribunal Constitucional sobre la segunda de estas limitaciones, restringió sobremanera las posibilidades de imposición de estos entes, al impedirles exigir tributos sobre las «materias imponibles», entendidas como fuentes de riqueza, ya gravadas por las entidades locales ${ }^{106}$. Sólo la modificación de la LOFCA a través de la Ley Orgánica 3/2009 amplió las potestades tributarias de estos entes, al permitirles ahora establecer tributos siempre que no recaigan sobre los hechos imponibles ya gravados por el Estado o las Corporaciones Locales.

El sistema alemán de distribución de competencias tributarias se asemeja, por otra parte, al vigente en España en los primeros años de desarrollo del Estado Autonómico, donde los presupuestos regionales se dotaban fundamentalmente de transferencias realizadas por la Administración central y de los ingresos procedentes de aquellos tributos estatales cuya recaudación se les había cedido en función de diversos puntos de conexión, aunque el titular del poder normativo continuara siendo el Estado. Tras la modificación de la LOFCA en el año 1996 y la introducción del principio de corresponsabilidad fiscal, las Comunidades Autónomas adquirieron importantes competencias normativas en relación con estos tributos. Así, a partir de este momento, tendrían la posibilidad de incrementar o minorar la recaudación que les correspondiera por alguno de ellos, mediante la modificación de alguno de sus elementos de cuantificación. Modulando la tarifa o el tipo de gravamen o introduciendo bonificaciones sobre los hechos imponibles realizados en su territorio, pueden las Comunidades Autónomas perseguir también fines diversos de política socio-económica. Entre los tributos cedidos sobre los que las Comunidades Autónomas tienen capacidad normativa se encuentran algunos de los tributos más relevantes del sistema tributario, como el Impuesto sobre la Renta de las Personas Físicas, el Impuesto sobre Sucesiones y Donaciones, el Impuesto sobre Transmisiones Patrimoniales y el Impuesto sobre el Patrimonio. Otros, como el IVA, sólo ven cedida su recauda-

106 Vid., sobre la interpretación de ambas prohibiciones, las sentencias del Tribunal Constitucional 289/2000, relativa al Impuesto Balear sobre determinadas Instalaciones que inciden en el medio ambiente; 168/2004, sobre el Impuesto Catalán sobre determinados elementos patrimoniales afectos a actividades de riesgo y las anteriores 37/1987 y 186/1993, sobre los impuestos andaluz y extremeño sobre tierras infrautilizadas. 
ción, sin poder incidir las autonomías en su régimen jurídico, dado su carácter armonizado.

La reforma de la LOFCA efectuada por Ley Orgánica 3/2009 y la subsiguiente aprobación de la Ley 22/2009, de 18 de diciembre, reguladora del sistema de financiación de las CCAA de régimen común, abundaron en la cesión de competencias normativas sobre estos tributos y ampliaron los porcentajes de cesión de su recaudación, que en los impuestos más relevantes como el IVA o el Impuesto sobre la Renta de las Personas Físicas alcanza el 50\% de lo recaudado en su territorio. Dada su autonomía tributaria, a las Comunidades Autónomas se les ofrece, así pues, la posibilidad de obtener una dotación financiera adecuada al ejercicio de sus competencias, sin perjuicio de que las diferencias económicas existentes desde el punto de vista territorial, den lugar a dotaciones complementarias de nivelación.

La capacidad de decisión de las Comunidades Autónomas en este terreno presenta en nuestro país dos problemas fundamentales semejantes a los apuntados en los debates sobre la reforma del federalismo alemán: la ruptura de la unidad del ordenamiento jurídico y la competencia fiscal entre distintos territorios, con importantes repercusiones sobre el principio de igualdad ${ }^{107}$. Las diferencias de tributación son, efecto, cada vez más acusadas entre los distintos territorios, con la práctica supresión del Impuesto sobre Sucesiones y Donaciones en algunas de ellas, la aplicación de tarifas y deducciones diversas en el Impuesto sobre la Renta de las Personas Físicas o de mínimos exentos distintos en el Impuesto sobre el Patrimonio, una vez recuperado por el Estado a través del Real Decreto-Ley 13/2011, de 16 de septiembre. También desde el punto de vista del principio de igualdad, el reconocimiento en nuestro país de regímenes tributarios especiales por razón del territorio, inexistentes en Alemania, ha presionado sobre la configuración del sistema en su conjunto.

La Constitución Española guarda silencio, por otra parte, sobre la organización de la Administración tributaria, que la LOFCA caracteriza como una Administración prioritariamente centralizada. Las Comunidades Autónomas gestionan no sólo sus propios tributos sino también aquellos de carácter cedido cuya recaudación les corresponde en su integridad. La Agencia Estatal de la Administración tributaria se ocupa, sin embargo, además de la gestión de los tributos estatales no cedidos, de aquellos otros cedidos parcialmente a las Comunidades Autónomas, a las que habrán de transferir las cantidades correspondientes. Las propuestas existentes en nuestro país para alcanzar una mayor descentralización en este terreno deben contrastarse con la experiencia alemana, ante las deficiencias del modelo descentralizado vigente en aquel país ${ }^{108}$.

Finalmente, es necesario realizar ciertas consideraciones en cuanto a la introducción del límite al endeudamiento público en el texto constitucional, cuyo análisis más detallado remitimos a otras colaboraciones incluidas en esta revista. Desde el año 2001, nuestro país contaba con una prolija legislación en materia de estabilidad presupuestaria,

107 Vid. también, sobre este particular, TEJERIZO LÓPEZ, quien propone la aprobación por parte del Estado de directivas similares a las existentes en Europa para evitar la competencia fiscal lesiva. La financiación territorial en los Estados descentralizados..., ob, cit., pág. 149.

108 Esta posibilidad se contempló en la propuesta inicial del Estatuto de Autonomía de Cataluña aprobada en septiembre de 2005 . 
orientada al cumplimiento de los compromisos europeos relativos al déficit público. La Ley 18/2001, de 12 de diciembre, General de Estabilidad Presupuestaria, y la Ley Orgánica 5/2001, Complementaria de la Ley de Estabilidad presupuestaria, recogían y desarrollaban este principio para el conjunto de las Administraciones públicas. Su reforma en el año 2006 flexibilizó la noción de estabilidad presupuestaria, que dejó de concebirse como equilibrio presupuestario anual, para permitir cierto endeudamiento en fases de menor crecimiento, tolerando, dentro de los límites comunitarios, un umbral máximo de déficit en función del crecimiento del PIB a repartir entre los distintos niveles territoriales, que habría de posibilitar la realización de una política económica anticíclica. Esta limitación se completaba con la posibilidad de incurrir en una cuantía adicional de déficit destinado a financiar incrementos de inversión en determinados programas. La reforma pretendió, además, la «determinación más negociada de los objetivos de estabilidad presupuestaria» entre el Estado y las Comunidades Autónomas, en el marco del Consejo de Política Social y Financiera ${ }^{109}$.

En este contexto, la modificación del artículo 135 de la Constitución ha venido a otorgar rango constitucional al principio de estabilidad presupuestaria. Dicha norma señala que «El Estado y las CCAA no podrán incurrir en un déficit estructural que supere los márgenes establecidos, en su caso, por la Unión Europea para sus Estados Miembros», ni superar «el volumen de deuda pública» del conjunto de las Administraciones, el valor de referencia establecido en el Tratado de Funcionamiento de la Unión Europea en relación con el producto interior bruto del Estado. Tales límites podrán superarse si concurren situaciones excepcionales como una catástrofe natural, una recesión económica u otras de emergencia extraordinaria «que escapen al control del Estado y perjudiquen considerablemente la situación financiera o la sostenibilidad económica o social del Estado, apreciadas por la mayoría absoluta de los miembros del Congreso de los Diputados». El artículo 135 remite, por otra parte, a una Ley Orgánica el desarrollo de estos principios y de «la participación, en los procedimientos respectivos, de los órganos de coordinación institucional entre las Administraciones Públicas en materia de política fiscal y financiera». Dicha norma regulará en todo caso: «a) La distribución de los limites de déficit y de deuda entre las distintas Administraciones Públicas, los supuestos excepcionales de superación de los mismos y la forma y plazo de corrección de las desviaciones que sobre uno y otro pudieran producirse; b) La metodología y el procedimiento para el cálculo del déficit estructural; c) La responsabilidad de cada Administración Pública en caso de incumplimiento de los objetivos de estabilidad presupuestaria».

Las similitudes entre este precepto y los artículos 109 y 115 de la Ley Fundamental son evidentes, aunque existen también diferencias notables que es preciso resaltar. Más allá de la recepción del principio de estabilidad presupuestaria, la norma española está integrada fundamentalmente por dos remisiones: la primera, al Derecho Comunitario para la fijación de los límites máximos del déficit y la deuda; y la segunda, a una Ley Orgánica, para el reparto del límite de déficit y la responsabilidad por su incumplimiento entre los distintos niveles territoriales, que habrá de regular también el procedimiento para el cálculo del déficit estructural. Los artículos 109 y 115 de la Ley Fundamental tie-

109 Cfr. J. CAAMAÑO ALEGRE y S. LAGO PEÑAS, «Evolución y problemas del marco de estabilidad presupuestaria en España: especial referencia a las Haciendas Autónomicas», M. VILLAR EZCURRA (Dir.) Estudios Jurídicos en memoria de D. César Albiñana García-Quintana, IEF, Madrid, 2008, págs. 3117. 
nen, en cambio, mayor contenido propio, al recoger de forma expresa los límites al endeudamiento que corresponden a la Federación y los Länder (0, 35\% del PIB para la Federación y nulo endeudamiento para los Länder) y la obligación de realizar simétricamente en fases de expansión y contracción, una política económica anticíclica, aunque la determinación del componente coyuntural del endeudamiento admisible se remita también al procedimiento desarrollado a través de una Ley Federal.

A la vista del contenido del artículo 135 y teniendo en cuenta la existencia de una normativa comunitaria limitativa del déficit y la deuda pública acumulada y de una previa legislación interna que adoptaba las medidas necesarias para su cumplimiento en cada nivel territorial, debe cuestionarse la necesidad de la reforma constitucional en nuestro país ${ }^{110}$. Como afirma MARTÍN QUERALT, «la mera previsión constitucional de este principio de estabilidad (...) pero dejando que sea una Ley Orgánica la que desarrolle tanto su límite específico como la forma de su cumplimiento y el régimen sancionador supone, ni más ni menos, cambiar algo — la CE— para que todo siga igual... pues es ya la Ley —Orgánica y ordinaria — la que realmente garantiza la pretendida estabilidad» ${ }^{111}$.

Las dudas sobre la conveniencia de constitucionalizar este principio derivan también de la dificultad de articular un efectivo control de constitucionalidad sobre el cumplimiento de estos límites, tanto por las Leyes de presupuestos como en fase de ejecución presupuestaria, dificultades que ya se habían puesto de manifiesto en Alemania en relación con la regulación constitucional previa a la reforma y que se mantienen en la vigente. En este país, la reforma era necesaria porque el límite anteriormente previsto en la Constitución divergía de los parámetros establecidos por las normas comunitarias y ante la inexistencia de una normativa interna previa que tendiera al cumplimiento de tales objetivos por parte de los distintos niveles territoriales. Esta situación diverge claramente de la existente en nuestro país antes de la reforma constitucional.

En nuestro ordenamiento, por otra parte, el problema de la adecuación de las limitaciones al endeudamiento autonómico a la autonomía financiera de las Comunidades autónomas no se plantea con motivo de la introducción del citado límite en la Constitución, al no existir en ella la protección reforzada existente en Alemania para el principio federal, que permite enjuiciar la constitucionalidad de las modificaciones introducidas en la

110 En este sentido, destaca FALCÓN Y TELLA que «la reforma constitucional no supondrá en la práctica más limitaciones que las ya previstas en el ordenamiento comunitario y las que se introduzcan por Ley Orgánica, lo que vacía de contenido jurídico al precepto. Ni siquiera puede interpretarse como una habilitación para limitar las competencias autonómicas mediante ley orgánica, pues el art. 157.3 ya prevé la regulación mediante ley orgánica de las competencias de las Comunidades autónomas sobre sus propios recursos, entre los que se encuentran las operaciones de crédito». Aunque la deuda pública española no haya alcanzado los niveles de otros Estados Europeos, que superan en muchos casos el 100\% del PIB, pues la deuda española a pesar de su rápido crecimiento escasamente sobrepasa el 60\% del PIB, su importe en euros «supone actualmente, junto con Italia, el mayor riesgo para el Banco Central Europeo, y por tanto para el euro, lo que explica que los accionistas mayoritarios nos hayan obligado a la reforma constitucional, aunque el texto aprobado prácticamente no contiene más que buenas intenciones, que habrán de concretarse en la Ley Orgánica de desarrollo», añade este autor. «La reforma del artículo 135 de la Constitución», Revista General del Derecho Europeo, núm. 25, 2011, págs. 4 y ss.

111 Cfr. J.MARTÍN QUERALT, «La constitucionalización del principio de estabilidad presupuestaria ¿una reforma realmente necesaria?», Tribuna Fiscal, núm. 252, 2011, pág. 7. 
propia Constitución. La adecuación de la legislación en materia de estabilidad presupuestaria a la autonomía financiera de las Comunidades Autónomas ha sido afirmada, por otra parte, por diversas sentencias del Tribunal Constitucional español, entre las que destaca la 134/2011, de 20 de julio. En ella se avala la constitucionalidad de las medidas de control estatal sobre los presupuestos autonómicos con fundamento en la competencia del Estado sobre la dirección de la actividad económica general, establecida en el art. 149.1.13 de la Constitución y en el principio de coordinación con la Hacienda estatal, recogido en el artículo 156.1, como condicionante a la autonomía financiera de las Comunidades Autónomas. Ya con anterioridad, la Ley Orgánica de Financiación de las Comunidades Autónomas exigía la autorización estatal para la contracción de ciertas operaciones de crédito por parte de las Comunidades Autónomas, que también había sido avalada por el Tribunal Constitucional con idéntico fundamento ${ }^{112}$. El debate existente en Alemania a este respecto, puede considerarse, por ello, resuelto en nuestro país a la luz de la doctrina reciente del Tribunal Constitucional.

TitLE: The Reform of the German Financial Constitution. The new limit to get into debt for Federation and States.

ABSTRACT: After the reform of the article 135 of the Spanish Constitution, to give constitutional status to the balanced budget principle and the public debt limits, this paper offers a comparative study with the equivalent rule of the German Constitution, as amended in 2009. The study explains the main characteristics of the distribution of taxing and spending power between the Federation and the States in the Bonn Basic Law and the reforms introduced in the previous revision of 2006. The article also outlines other issues discussed during the reform process, like the tendency to a centralized Tax Administration and the growing but still very limited State Tax Powers.

RESUMEN: Ante la reciente reforma del artículo 135 de la Constitución Española para dotar de rango constitucional al principio de estabilidad presupuestaria y establecer límites a la deuda y déficit públicos, el presente trabajo realiza un estudio comparativo con la revisión constitucional efectuada con igual finalidad en el año 2009 en la Ley Fundamental de Bonn. Para ello se parte de la exposición de las características esenciales del reparto territorial de competencias financieras en la Constitución alemana y de las modificaciones introducidas sobre el mismo en la reforma previa del año 2006. El estudio analiza, así mismo, otros aspectos discutidos durante el proceso de reforma constitucional, como la tendencia hacia la centralización de la Administración Tributaria y el incipiente, aunque muy limitado, incremento de la autonomía tributaria de los Länder, también de interés para nuestro país.

KEYWORDS: Constitutional reform. Territorial distribution of taxing and spending power. Fiscal Federalism. Bonn Basic Law. Financial German Constitution. Public Debt limit.

Palabras Clave: Reforma Constitucional. Relaciones financieras interterritoriales. Federalismo fiscal. Ley Fundamental de Bonn. Constitución financiera alemana. Limite al endeudamiento público.

FeCHA DE RECEPCIÓN: 14.01.2012 FeCHA DE ACEPTACIÓN: 15.02.2012.

112 Vid., entre otras, las Sentencias del Tribunal Constitucional 179/1987, de 12 de noviembre y 87/1993, de 11 de marzo. Sobre la problemática de la adecuación de la normativa de estabilidad presupuestaria a la autonomía financiera de las Comunidades Autónomas, vid. entre otros, M. A. MARTÍNEZ LAGO, «Estabilidad presupuestaria y autonomía financiera de las Comunidades Autónomas», Noticias de la Unión Europea, núm. 22, 2006, Págs. 57 y ss y F. ALONSO MURILLO, «Incidencia de la reforma de las Leyes de Estabilidad Presupuestaria en las Comunidades Autónomas», Revista de Información Fiscal, núm 91, 2009, págs. 41 y ss. 